\title{
Development of a Greenhouse Tobacco Seedling Performance Index
}

\author{
by \\ Jodie J. Clarke \\ Thesis submitted to the Faculty of \\ Virginia Polytechnic Institute and State University \\ in partial fulfillment of the requirements for the degree of \\ Master of Science \\ in \\ Crop and Soil Environmental Sciences
}

Approved:

Dr. T. David Reed, Chair

Dr. James L. Jones

Dr. Carol A. Wilkinson

Dr. Gregory E. Welbaum

July, 2001

Blacksburg, Virginia

Key Words: digital image analysis, emergence, seedling performance, tobacco 
Development of a Greenhouse Tobacco Seedling Performance Index

Jodie J. Clarke

(ABSTRACT)

Tobacco seed performance is traditionally measured as percentage germination at $14 \mathrm{~d}$ under controlled laboratory conditions. However, under greenhouse conditions, seed lots with equal 14-d germination may exhibit substantial differences in uniformity of early seedling growth and spiral root incidence that impact the number of usable transplants. A seedling performance index (SPI) was developed to quantitatively describe greenhouse tobacco seedling performance. The 14-d emergence, relative leaf area uniformity, and seedling leaf area determined by computer image analysis were used to calculate the index. Greenhouse tobacco seed trials demonstrated that seed with the Rickard pellet had higher emergence, but the higher spiral root incidence associated with the Rickard pellet lowered the SPI compared to the Cross Creek pellet. Primed seed lots of flue-cured cultivars (NC 72 and NC 71) had a significantly higher SPI than the nonprimed seed lots at one location but not at a second location. Seed lots sown in Premier Pro-Mix TA commercial medium had a higher spiral root incidence, which resulted in a lower SPI compared to Carolina Choice, Carolina Gold, and Sunshine LP5 commercial media. The index quantitatively determined differences in seedling performance under greenhouse conditions not reflected by standard germination tests. Significant differences in the SPI were observed among seed lots with certified $90 \%$ germination. The SPI is a simple method to describe seedling performance because the data used to calculate the SPI is obtained from one seed tray image. In contrast, frequent counting and seedling evaluations are involved with standard germination and vigor tests. 


\section{ACKNOWLEDGEMENTS}

I extend special gratitude to Dr. David Reed for allowing me the opportunity to conduct research in his program at Southern Piedmont Agricultural Research and Extension Center (SPAREC). His assistance, devotion, and guidance throughout my graduate program provided me with a strong, working knowledge base and many opportunities to grow and develop as a person as well as a professional. I thank Dr. James Jones for providing counsel and excellent facilities for conducting research. A special thanks goes to Dr. Carol Wilkinson for her assistance during the final phases of the thesis revision. Her expertise, encouragement, and dedication to finishing my thesis aided me through the remainder of my graduate program. Appreciation is also extended to Dr. David Parrish and Dr. Greg Welbaum for their participation as members of this graduate committee.

I acknowledge the financial support of Profigen that allowed me the opportunity for graduate study involving the crop that has been such an important part of my life. I express sincere appreciation to Mr. Bill Wilkinson and the entire field staff at SPAREC for their assistance during the research studies. A special thanks goes to Danny Powers for his assistance with the greenhouse studies, and Randy Maitland for his friendship in addition to his assistance, throughout my entire experience at SPAREC. Additional appreciation is extended to Margaret Kenny and Mac Tilson at SPAREC, with special acknowledgement to Betty Lou Mayton whose walking breaks and friendship kept me going in the toughest times. I thank fellow graduate students, Scott Jerrell and Barabar Crowder, who aided me in times of image capturing. I thank Daniel Allen, Maureen Currin, Erin Jones, Rachel Manning, Patrick Mansfield, Brandon Schmidt, and Aaron Syracuse for their assistance in conducting research. I also am grateful for all the

growers who offered facilities and assistance in conducting my research that made 
this thesis possible. I appreciate Bruce Jones, Extension Agent, ANR, tobacco in Pittsylvannia County for his support and assistance in conducting research.

Words simply cannot say how much I appreciated the assistance and support of my husband, C. Taylor Clarke, Jr., Extension Agent, ANR, tobacco in Brunswick and Mecklenburg County. His devotion to my research and me aided me in completing my master's degree. I also thank his family for their interest in my education. In addition to all the people above whom provided me assistance, I extend a special appreciation to my family. They remained supportive of me in the toughest times of my life and instilled a work ethic in me along with a passion and deep respect for tobacco and agriculture in general that has helped me get to where I am today. 


\section{TABLE OF CONTENTS}

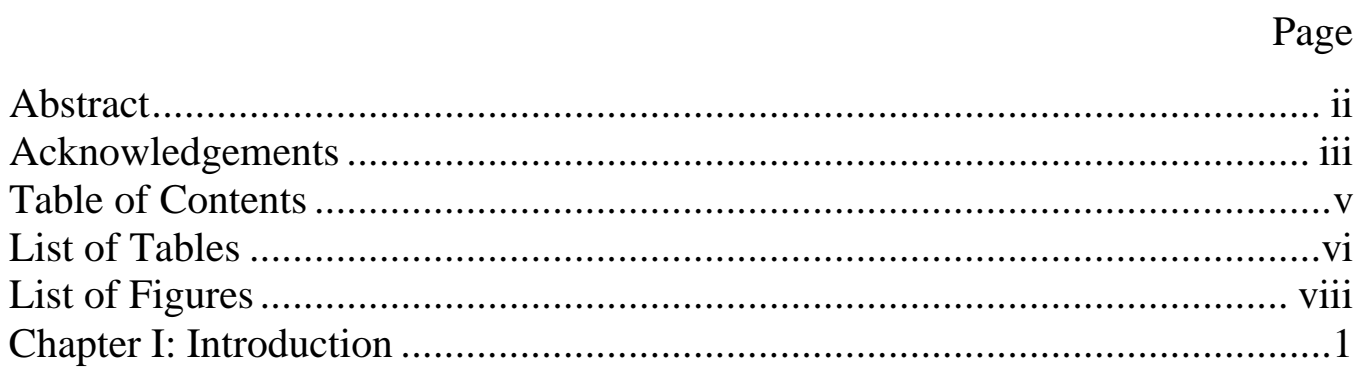

Chapter II: Literature Review ...............................................................6

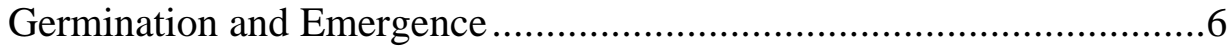

Factors Affecting Germination of Tobacco Seed ..................................7

Poor Germination and Nonuniform Emergence of Tobacco Seed .........10

Treatments for Tobacco Seed ..........................................................10

Determining Seed Vigor ......................................................... 12

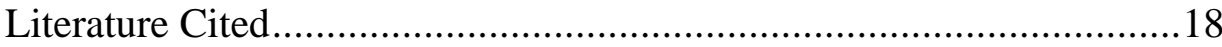

Chapter III: Development of a Greenhouse Tobacco Seedling Performance

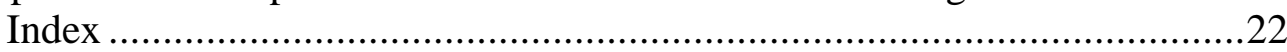

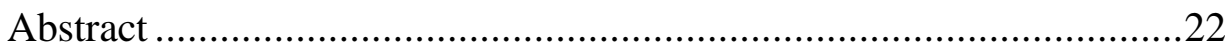

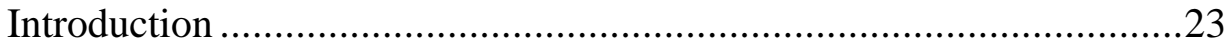

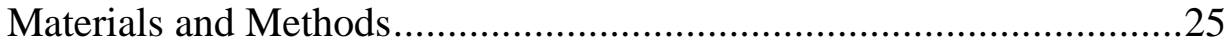

Results and Discussion .........................................................28

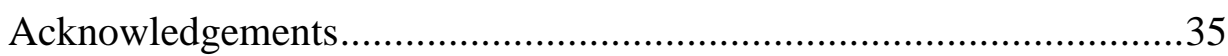

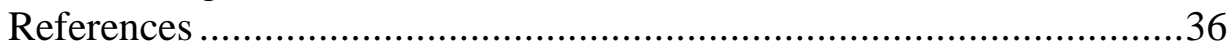

Chapter IV: Using a Seedling Performance Index to Evaluate Greenhouse

Tobacco Seedling Production .................................................................52

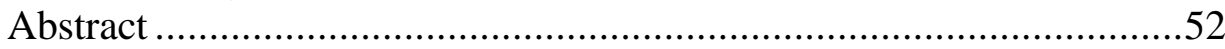

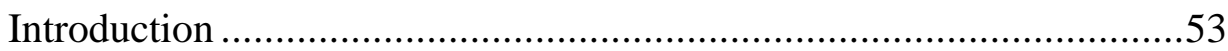

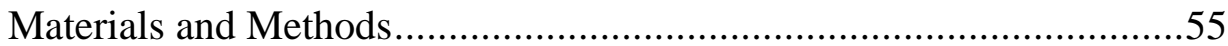

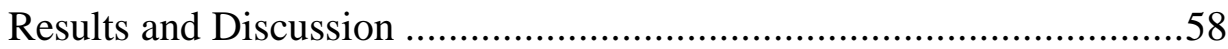

Acknowledgements.................................................................63

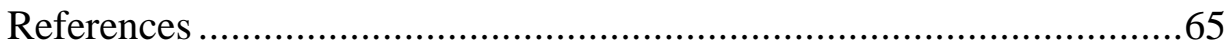

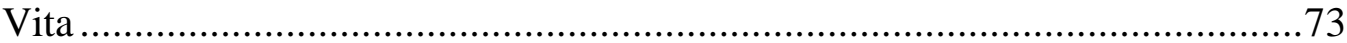




\section{LIST OF TABLES}

Table

Page

3.1 Influence of weighting factors on the seedling performance index (SPI) using one seed lot of flue-cured tobacco cultivar NC 72 with four seed enhancements, Clary greenhouse, Mecklenburg County, Virginia 38

3.2 Influence of weighting factors on the seedling performance index (SPI) using one seed lot of flue-cured tobacco cultivar NC 72 with four seed enhancements, Harrison greenhouse, Brunswick County, Virginia

3.3 Influence of weighting factors on the seedling performance index (SPI) using one seed lot of flue-cured tobacco cultivar NC 72 with four seed enhancements, SPAREC greenhouse, Nottoway County, Virginia

3.4 Seedling performance data for one seed lot of flue-cured tobacco cultivar NC 72 with four seed enhancements, Clary greenhouse, Mecklenburg County, Virginia

3.5 Seedling performance data for one seed lot of flue-cured tobacco cultivar NC 72 with four seed enhancements, Harrison greenhouse, Brunswick County, Virginia

3.6 Seedling performance data for one seed lot of flue-cured tobacco cultivar NC 72 with four seed enhancements, SPAREC greenhouse, Nottoway County, Virginia

3.7 Seedling performance data for four seed lots of flue-cured tobacco cultivar NC 71, Lynch greenhouse, Brunswick County, Virginia

3.8 Seedling performance data for four seed lots of flue-cured tobacco cultivar NC 297, SPAREC greenhouse, Nottoway County, Virginia

4.1 Effect of pellet material and cultivars on seedling performance, Thomas greenhouse, Brunswick County, Virginia 
4.2 Effect of pellet material and cultivars on seedling performance,

SPAREC greenhouse, Nottoway County, Virginia. ........................... 67

4.3 Effect of priming on seedling performance of three flue-cured tobacco cultivars, Clary greenhouse,

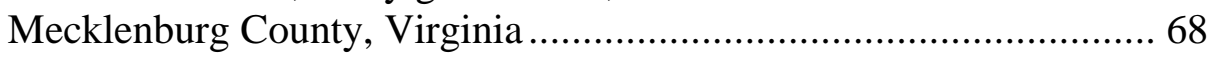

4.4 Effect of priming on seedling performance of three flue-cured tobacco cultivars, Harrison greenhouse, Brunswick County, Virginia

4.5 Effect of five media on seedling performance data for two flue-cured tobacco cultivars, Thomas greenhouse, Brunswick County, Virginia

4.6 Effect of four media on the seedling performance index of four seed lots of flue-cured tobacco cultivar NC 71, Emerson greenhouse, Pittslyvannia County, Virginia

4.7 Effect of four media on the seedling performance index of four seed lots of flue-cured tobacco cultivar NC 297, Emerson greenhouse, Pittslyvannia County, Virginia 


\section{LIST OF FIGURES}

Figure Page

3.1 Example image of tray at $14 \mathrm{~d}$ after seeding, Lynch greenhouse, Brunswick County, VA ........................................................ 46

3.2 Acquisition of image of one seed lot ............................................. 47

3.3 Selection of color classes for leaf area analysis ............................... 48

3.4 Calibration of software for leaf area analysis from image .................... 49

3.5 Image of relatively uniform seed lot with a calculated SPI

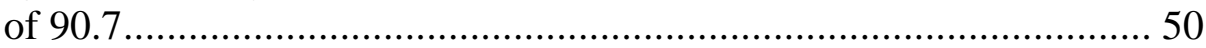

3.6 Image of relatively nonuniform seed lot with a calculated SPI

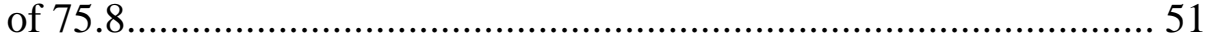




\section{Chapter I}

\section{Introduction}

Greenhouse transplant production has replaced outdoor plant beds and has become the standard over the past decade for flue-cured tobacco (Nicotiana tabacum L.) producers in Virginia and much of the southeast United States. Reed et al. (2001) estimated that $98 \%$ of Virginia's flue-cured tobacco acreage was planted with transplants produced in float-system greenhouses. The float-system is a subirrigation system, where the bottom of the trays are in contact with the water or nutrient solution. Capillary action in growing media carries the water to the seed, which resides on the surface of media filling the tray cells (Reed, 1996). An advantage of greenhouse transplant production over outdoor plant beds is increased uniformity of transplants, but disadvantages include poor, slow, and/or nonuniform seedling emergence, and spiral roots (Reed et al., 2001). Producers often attribute these problems to seed quality, although other production factors, such as media, may also play a role in producing quality transplants.

Emergence, uniformity, and vigorous growth of each tobacco seedling are essential to successful transplant production. The seeding rate of outdoor plant beds typically exceeded the number of defined transplants five fold. Greenhouses are typically seeded with $10 \%$ to $15 \%$ extra seed to account for normal stand

losses. Variability associated with tobacco seed emergence has become a greater issue with greenhouse producers because of the reduced overproduction of transplants. Delayed and prolonged emergence produces nonuniform transplants. Producers recognize that a reduction in time necessary for germination and seedling establishment lowers costs and promotes transplant uniformity (McDonald, 2000).

Uniform and large seedlings ease the task of transplanting. Some size variation among seedlings is related to time of emergence (Cundiff, 1979). 
Because of the variability in emergence, a young tobacco seedling may not be useable as a transplant at the same time as the majority of other seedlings in the tray. Clipping is an essential management practice that increases seedling uniformity, but even with proper clipping, elimination of smaller seedlings is impossible (Reed, 1997). Producers are aware that certain seed lots yield a greater number of smaller seedlings than another seed lot. Producers detect differences in seed lot performance as early as $14 \mathrm{~d}$ after seeding based on seedling growth and emergence patterns. Tobacco seed companies evaluate tobacco seed solely on the standard germination test, which is performed in a growth chamber under optimal conditions. No other seed or seedling evaluations are performed. Greenhouse conditions differ greatly from laboratory conditions, so seedling emergence and growth may not reflect a seed lot's tested germination.

Differences in emergence and seedling growth have magnified problems associated with high soluble salt concentrations in different media and fertilizers used in transplant greenhouses. Prolonged and delayed emergence produce nonuniform transplants with a higher proportion of small seedlings, which may be sacrificed to fertilizer salt injury because of the high rates of evaporation that occur in greenhouses during the spring. Evaporation from the media surface leaves a high concentration of salts where a young seedling's root is exposed. High salt concentrations will not harm a larger seedling after its root has penetrated the media surface, but late germinating seeds expose a sensitive radicle to high salt concentration, and mortality of the seedling is often the result. Germination and emergence may be reduced or delayed with high concentrations of soluble salts (Hoyert, 1968).

Spiral roots can influence seedling growth and uniformity. Tobacco seedlings may form spiral roots, roots that grow or "spiral" on the media surface rather than penetrate the medium. These roots seem to lack the normal gravitropic response that results in downward root growth. A spiral root may 
eventually penetrate the medium to produce a normal seedling or the seedling may develop a secondary root that grows normally. A greater number of spiral roots increases the probability of a nonuniform population and therefore unusable transplants. If a spiral rooted seedling does not penetrate the media soon after emergence then the young seedling will die. Spiral root incidence has increased in the float-system greenhouses in recent years. Seed quality may be one of many factors that interact to cause spiral roots (Reed et al., 2001). Some primed seed lots, especially within particular cultivars, have increased spiral root numbers (T.D. Reed, unpublished data, 2001). Producers view spiral root seedlings as weak plants, but the effect of these seedlings on the growth and uniformity of tobacco seedlings has not been quantitatively determined.

Seed companies introduced "primed" tobacco seed in 1997 in an effort to overcome nonuniform seedling emergence. The priming or osmoconditioning process, which serves to enhance seedling uniformity by improving germination and emergence, is delicate, and the stages of the process must be implemented with extreme care. Studies have documented the process, as well as the effect of osmoconditioning on many species of plants (Kahn, 1992). The effects of priming on tobacco seedling emergence and growth are variable and have not been quantitatively determined.

Seed germination and rapid, uniform seedling growth are critical for the production of viable, uniform tobacco seedlings in a float-system greenhouse. There are no methods to quantify uniformity in seedling emergence and subsequent seedling growth. The germination guaranteed by the seed company may be indicative of the germination of the seed in a petri dish under controlled environmental conditions, but it may not be indicative of how the same seed lot will perform under greenhouse conditions.

Seed vigor tests were designed to provide additional information about the physiological quality of a seed lot that may not be available from a standard 
germination test. Seed germination and vigor tests do not provide information about seedling growth. Seedling evaluations, which describe seedling growth of a plant species, do not exist for tobacco. Greenhouse seedling production must begin with rapid and uniform emerging seeds that will produce transplants of similar size and quality. Seeds used for transplant seedling production must be very high in vigor potential (Ferguson, 1993).

In an effort to expand on current knowledge of tobacco seed and transplant production, the objectives of this research were to:

i). Develop a greenhouse tobacco seedling performance index using emergence, germination rate, and leaf area measured by computerized image analysis,

ii). Calculate the greenhouse tobacco seedling performance index associated with commercially available seed lots of flue-cured cultivars, and to

iii). Determine the effect that different greenhouse production factors might have on different seed lots by examining emergence, germination rate, and seedling performance. 


\section{Refernces}

Cundiff, J.S. 1979. Tobacco seed emergence related to differences in terminal velocity. Tob. Sci. 23:49-51.

Ferguson, J.M. 1993. AOSA perspective of seed vigor testing. J. Seed Technol. 17:101-04.

Hoyert, J.H. 1968. Germination (emergence) of tobacco seed and its relationship to total soluble salts as measured by electrical conductivity of the soil. Tob. Sci. 11:35-36.

Kahn, A.A. 1992. Preplant physiological conditioning treatments. Hortic. Rev. 13:131-181.

McDonald, M.B. 2000. Seed viability, germination, and vigor: Sorting out the terminology. p. 29-31. In J. VanderVelde (ed.) GrowerTalks on Plugs 3. Ball Publ., Batavia, IL.

Reed, D.W. 1996. A grower's guide to water, media, and nutrition for greenhouse crops. Ball Publ., Batavia, IL.

Reed, T.D. 1997. Float greenhouse tobacco transplant production guide. Publ. 436-051. VA Agric. Exp. Stn., Blacksburg, VA.

Reed, T.D., J.L. Jones, C.S. Johnson, P.J. Semtner, and C.A. Wilkinson. 2001. 2001 Flue-cured tobacco production guide. Publ. 436-048. VA Agric. Exp. Stn., Blacksburg, VA. 


\section{Chapter II}

\section{Literature Review}

\section{Germination and Emergence}

Germination of a tobacco seed is essential in establishing viable transplants that will be used in producing a high yielding crop. Tobacco has been a commercially important crop for $350 \mathrm{yr}$, yet abnormal emergence and seedlings associated with tobacco seed germination have often been ignored. Germination begins with water uptake by the seed (imbibition) and ends with the start of elongation by the embryonic axis, usually the radicle. Germination can be categorized into a triphasic pattern of water uptake that begins with rapid imbibition (phase I), followed by a plateau or lag phase in which there is little change in water content (phase II), and a final increase in water content coinciding with radicle growth (phase III) (Bewley and Black, 1994). Germination percentages express the proportion of seed reaching the final stage of emergence, but reveal nothing about the time taken to reach this stage (Desai et al., 1997). Germination rates express the degree of germination over a designated time period as a percentage of the population (Bewley and Black, 1994). The purpose of a germination test is to determine how seed perform under optimal conditions; conditions rarely encountered in the greenhouse or field (McDonald, 2000).

A seed analyst defines germination by the emergence and development of essential plant structures and considers it as a signal of the seed's ability to produce a normal plant. A seed technologist measures germination only after a normal plant is observed. A producer counts seedlings that are emerged from the soil, and often will only count those which are usable (Cantliffe, 2000). Seed are always tested under favorable conditions, so it is unusual that growers achieve 
germination percentages in the greenhouse that are reported on the seed package label (McDonald, 2000).

\section{Factors Affecting Germination of Tobacco Seed}

Hutchens (1999) referred to tobacco as possibly the smallest seed of all major horticultural and agricultural crops. Germination is affected by many factors, such as light and temperature. The temperature under which the mother plant was grown has been shown to affect the plant's resulting progeny as well as seed germinability of progeny seed (Thomas and Raper, 1975). The effects on the mother plant affect germination and seedling vigor before the conditions that the seed experiences upon germination become a factor. Seed size has been shown to influence germination. Environmental conditions when seed are produced can affect their weight distribution into various grades (Smith et al., 1973). Cundiff (1979) demonstrated that seed lifted by higher terminal air velocities, which was indicative of heavier seed, had a higher germination percentage than lighter seed. Tso (1990) reported that heavier tobacco seed had a higher percentage of early germination over a shorter period of time. In addition to seed size, other environmental effects on germination are a result of the time when the seed were formed. Duration of the stress must also be considered, as well as the developmental stage of the plant that is exposed to the stress (Bewley and Black, 1994). Some of these seed forming periods could occur under stressful conditions, such as low water availability, high or low temperature stress, nutrient deficiencies, and shading.

Thomas and Raper (1979) found that nitrogen (N) fertilization of the mother plant could affect seed germination. Increased $\mathrm{N}$ applied to the mother plant reduced days to obtain seed germination and enhanced the uniformity of seed germination (Thomas and Raper, 1979). Gywn (1973) showed how seed maturity affected the germination of seed from six different cultivars. Seed harvested $14 \mathrm{~d}$ after anthesis proved to be viable, but germination was lower than 
with seed harvested $22 \mathrm{~d}$ after anthesis (Gywn, 1973). These effects may be realized in the seed lots obtained from plants harvested earlier after anthesis. Removing top leaves, trimming the seed head, and bagging the fruits have been shown to lower seed yield on mother plants and germination of harvested seed (Nichols and Davis, 1965). Germination may be variable among seed populations because of the different situations in which seed are formed, and this results in a nonuniform emerging plant population.

The manner in which seed are handled and stored, as well as the period during which the seed is harvested, may have an effect on resulting germination and seed vigor. Seed may be harvested from the entire inflorescence where all seed may not be mature, or the seed may be harvested from individual buds when mature. If the seed is either aged or immature, adverse effects on germination could result (Gwynn, 1973). Storage is the key to maintaining high seed quality from seed harvest to sowing. During storage, seed vigor decreases before viability, which is the ability of a live seed to germinate under optimum conditions. When two seed lots are stored for a period of time, although both have tested $90 \%$ germination, one seed lot will often have a declining vigor curve, while the other seed lot will not (Cross and Styer, 2000). Seed storage at high temperature and high relative humidity can rapidly reduce seed germination and seedling vigor (Cantliffe, 2000).

Germination of seed and seedling vigor can be affected by temperature and light conditions in the greenhouse (Bunn and Splinter, 1961). As the optimum temperature changes, germination is reduced rapidly, and the most rapid germination rate occurred when temperatures were 26 to $32^{0} \mathrm{C}$ (Bunn and Splinter, 1961). Genotypes with superior heat tolerance are more likely to result in a uniformly germinated stand (Koroma et al., 1996). Bunn and Splinter (1961) examined the effects of temperature, moisture, and light on the germination percentage of flue-cured tobacco seed, while Kasperbauer (1968) showed 
inconsistency in germination of tobacco seed with respect to light sensitivity. Bunn and Splinter (1961) stated that temperature has a more pronounced effect on germination probability than either soil moisture or wavelength of light, although it has been established that tobacco requires light to germinate. Kasperbauer (1968) demonstrated that germination varied considerably among lots of the same cultivar as well as among lots of different cultivars. The importance of quantity of light, as well as the effects of seed treatments in overcoming light quantity requirements, is not known. The quality, quantity, and intensity of light may affect the light treatments.

In addition to light and temperature, the nutrient concentration, $\mathrm{pH}$, and water-holding capacity of media, as well as the shape of the medium after it has been dibbled will impact seedling growth (Styer and Koranski, 1997). Research has shown that spiral root incidence is less with a pyramid dibbler than with a spherical dibbler because more of the force is concentrated on medium in the center of the cell where the seed lies (Reed et al., 2001).

Maximizing germination depends heavily on the ability to optimize and control soil temperature and moisture at the seed level for a specific crop (Styer and Koranski, 2000). Tobacco seed germinates at an optimum temperature range of 18 to $23^{0} \mathrm{C}$. Within this optimum range, most germination will usually occur between 7 to 12-d after seeding. Lower temperatures may delay emergence thereby increasing nonuniformity, while higher temperatures may actually decrease germination (Hutchens, 1999). Crops differ in the optimum soil moisture for germination. Commercial tobacco and a popular bedding plant are in the genus Nicotiana. Species of this genus have shown to favor soil with a medium moisture level for the first two phases of germination. Producers describe moderate moisture as moisture, although not visible on the surface, is apparent to the touch, and the media is not light colored (Styer, 2000). A germinating tobacco seed can perish in less than $4 \mathrm{~h}$ under droughty conditions. 
In contrast, an over-abundance of moisture is one of the leading causes of poor germination and seedling failure in float-system greenhouse production (Hutchens, 1999).

\section{Poor Germination and Nonuniform Emergence of Tobacco Seed}

Cundiff et al. (1978) demonstrated that plants that emerged $2 \mathrm{~d}$ apart were significantly different in size, and therefore homogeneity at $55 \mathrm{~d}$ of age. Survivability of later germinating plants was also lowered (Cundiff et al., 1978). They also reported that day of emergence had a significant effect on total plant height and had a greater effect on size than nutrition. With regard to nutrition, high concentrations of soluble salts in contact with germinating seeds may reduce emergence. High soluble salt concentrations may actually kill young seedlings, especially later emerging seedlings (Hoyert, 1968). Seedling emergence is an important factor in transplant variability (Cundiff, 1979). Variability in seedlings may be present throughout the life cycle of these plants. Germination tests document seed viability, but not nonuniform emergence, which influences seedling vigor. A seed lot may have high germination rates, but the seedling vigor may be variable, resulting in a nonuniform population of plants.

Nonuniformity hinders mechanical treatments in greenhouses and the competitive ability of smaller plants for light and nutrients.

\section{Treatments for Tobacco Seed}

Seeds are often treated to achieve improvements in germination such as more uniform emergence. Light treatments affect germination rates, with germination being stimulated by white light (Bewley and Black, 1994). Another treatment is priming, also known as osmoconditioning. Priming is a process that begins germination so that populations emerge more uniformly (Kahn, 1992). Osmoconditioning or priming is a process that begins germination so that more uniformly emerging populations exist. Priming partially hydrates seeds so that germination processes begin, but radicle emergence does not occur. The process 
is stopped theoretically at the end of phase II of germination, and the seed is dehydrated. Phase III is characterized by water being imbibed and radicle emergence occuring, so when the seed is rehydrated germination will proceed. The theoretical objective of priming is to have all seeds at the same stage in germination so that a more uniformly emerging population of seedlings is obtained. The priming process also aids certain species with physiological processes in germination that are not easily overcome by the seed itself. The priming process will therefore hasten germination. In some stress situations, such as lower temperature, germination is improved by priming (Welbaum et al., 1998). Priming decreased the thermoinhibition and thermodormancy in many lettuce cultivars (Kahn, 1992). If seed quality was optimal then treatment may not be necessary to obtain uniform germination and emergence because seed treatments can have an adverse effect on seed quality. Many factors, such as duration, temperature, osmotic concentration, rehydration period, and the storage of the seed post-treatment, affect the results of the osmoconditioning treatment (Welbaum et al., 1998). Primed tobacco seed has been shown to germinate faster and maintain higher germination rates at a wider temperature range than seed that has not been primed, in a few circumstances. Primed tobacco seed is reported to germinate more uniformly, although the results are inconsistent (Hutchens, 1999).

Primed tobacco seed is used infrequently, but all tobacco seed used in greenhouses is pelleted. Pelleting, adding foreign material to the seed surface, increases the seed size. Pelleting tobacco seed has become necessary in precision-seeded transplant production. Pelleting allows tobacco seed to be more accurately placed on the soil surface, remain positioned at a precise depth, and enables mechanical handling of the individual seed (Hutchens, 1999). The material may also help maintain proper moisture around the seed. Gwande et al. (1980) concluded that pelleting may also provide protection against thermal stress by reducing the rate of temperature change around the seed. Pelleting seed has 
been shown to delay emergence by one day compared to uncoated seed. Pelleting changes the overall shape of the seed and the fluorescent dyes used in pelleting allow the seed to be more visible in the plug tray after seeding (Styer and Koranski, 1997). Pelleted seeds do not store as long as conventional seeds, so only recently pelleted seed should be purchased (Cantliffe, 2000).

The effects of seed treatments and the pellet are detected as measurements of the germination rate of the seeds, where nothing is revealed about the size of the seedling as it reaches the final emergence stage. Seedling vigor is affected by germination and all the variables that affect germination; so, by examining germination characteristics and the treatments to improve germination, one may better understand the method to obtain a more vigorous seedling.

The seed itself must be examined thoroughly in order to derive conclusions on germination and seedling vigor as well as the effectiveness of seed treatments to improve the germination and emergence rate of a population. The viability of a seed is determined by the properties of the uncoated seed, and many genetic as well as environmental factors play a role in the germination of a seed by their effects on the properties of the seed. Genetic factors are inherited in the genome of the seed and are relatively stable over time. Environmental factors vary spatially and temporally over the life span of the seed, especially during its development and germination (Bewley and Black, 1994). Little is known about seed development stages in many plant species. There is a relatively small amount of information about tobacco seedling development, and more is needed to determine if the variable effects seen in germination are due to seed quality. The germination of a seed is the beginning of the plant's life and therefore productivity of that plant (Bewley and Black, 1994).

\section{Determining Seed Vigor}

A number of methods are available to analyze seed germination data. The percent germination of a particular tobacco seed lot has been the traditional 
measure of seed quality. This was adequate for traditional outdoor plant beds, where as much as five times the number of seed were sown for the number of transplants needed. With the development of float-system greenhouses to produce transplants, where only about $10 \%$ more seed are sown than needed, traditional thinking about seed quality has been challenged. Highly germinating in addition to highly vigorous seed are necessary (Hutchens, 1999). Scott et al. (1984) summarized many of the existing methods for analysis of seed germination. None of the methods indicate anything about uniformity of the seedlings. Uniformity of seedlings is gathered from the germination rate, with seed that germinate in a shorter time frame having more uniformity than seed that germinate across a longer time frame (Scott et al., 1984). The germination index (GI) is one example of measuring uniformity by time to germination and is calculated as:

$$
\mathrm{GI}=\sum \mathrm{T}_{\mathrm{S}} \underline{\mathrm{N}}_{\mathrm{i}} \text {, where } \mathrm{T}_{\mathrm{i}} \text { is the number of }
$$

days after sowing, $\mathrm{N}_{\mathrm{i}}$ is the number of seeds germinated on day $\mathrm{i}$, and $\mathrm{S}$ is the total number of seeds sown. A small GI is indicative of a more rapid germination time. This measure is relatively simple to calculate, but confounds effects contributed by the time of germination with the number of seeds responding, and it provides no information about the distribution of germination events over time (Scott et al., 1984). This is not a problem if most seeds germinate. Since Scott et al. (1984) reviewed measures of germination, probit analysis was invented and germination rate has become the standard for assessing seed quality. The inverse of the germination rate is the mean time to germination (G.E. Welbaum, personal communication, 2001).

Mohapatra (1993) used germination synchrony to examine the light requirement of seed from different flue-cured tobacco cultivars. Germination synchrony was expressed as $\mathrm{HG} / \mathrm{FG}$, where $\mathrm{HG}$ is highest germination percentage 
during any $24 \mathrm{~h}$ period and FG is final germination percentage (Mohapatra, 1993). Germination synchrony may be indicative of the emergence pattern occurring, but reveals nothing about the size and uniformity of the seedlings. Seed vigor is intended to be a more sensitive measure of seed quality. The objective of seed vigor tests is to more accurately predict how a seed lot will perform under the stresses of greenhouse production (McDonald, 2000). Seed vigor could be used as an predictor of the amount of time that it takes to reach the final stage of emergence. Vigor can be defined as sum total of all seed attributes that favor stand establishment under unfavorable conditions. The Association of Official Seed Analysts (AOSA) defines seed vigor as the sum total of all those properties in seed that, upon planting, result in rapid and uniform production of healthy seedlings under a wide range of environments, including unfavorable and stressful conditions (AOSA, 1983).

The Vigor Subcommittee of the Association of Official Seed Analysts describes six characteristics of a practical vigor test. The vigor tests must be reproducible. The test should provide an easy interpretation and be a good indication of field performance. The test needs to be rapid and economically practical, as well as simple, but objective. Subjective interpretation increases variation in results among laboratories (TeKrony, 1982). The International Seed Testing Association (ISTA) stated that the germination test remains the principal and accepted criterion for seed viability, but vigor testing should be used to provide further information on the potential performance of high germinating, greater than 90\%, seed lots (Hampton, 1993).

The concept and potential benefits of measuring seed vigor have been recognized for years. Seed vigor testing first became important in the late 1940s with the development and use of the cold test for corn (Zea mays L.) (TeKrony, 1982). The most frequently given purposes for vigor testing were to predict stand establishment and to select seed lots for planting. Crop uniformity was least 
frequently mentioned (Grabe, 1976). Although uniformity was less frequently mentioned, it directly influences stand establishment as well as selection of seed lots. Seed vigor testing is not performed on tobacco seed, but seedling evaluations have been performed. Csinos and Ghate (1982) examined coefficients of variability of plant size for differences in a study involving fluid sowing of pregerminated tobacco seed, and indirectly evaluated tobacco seedling growth.

However, there is increased interest in vigor testing in the vegetable and flower seed market. The accelerated-aging test is the dominant procedure used for vigor testing of flower and vegetable seed (McDonald, 1993). The acceleratedaging test is considered the most universally adaptable seed vigor test, because it is easily standardized (McDonald, 2000). Vigor tests are often used by seed companies to determine which seed lots are strongest, and in some instances, predict how long a seed lot can be stored (Cantliffe, 2000). Increased interest of seed vigor by farmers has also contributed to vigor testing (TeKrony, 1982). As a result of the increased interest in seed vigor, seed vigor testing has emerged as a routine method to test seeds for field performance capability (McDonald, 1993). McDonald (1993) attributes the development of seed vigor testing to deficiencies in the philosophy of the purpose of a standard germination test. Many vigor tests are not applicable to tobacco seed because of its small size, but seedling growth and evaluation tests can be used to determine seedling performance (AOSA, 1992).

The Paradigm Seedlot Vigor Assessment system was developed from a new domain of vigor test that use computer image analysis (Hopkins, 1996). The Paradigm Seedlot Vigor Assessment system uses digital images of seedlings taken on blotter paper, and radical length is measured to calculate a vigor index (McNertery, 1999). The Ball Vigor Index (BVI) is a computer program used by Ball Seed Company to predict transplant usability (Shaw, 2000). Ball Seed 
Company utilizes image analysis of cotyledon expansion. Imaging technology is one of many new ideas to improve seed testing and reporting of seed testing results. Computer images are analyzed objectively and rapidly. Imaging processes may be automated to record and process very small changes in seedling growth on an hourly basis if necessary. Collection of the images for analysis is easy, but challenges exist in interpreting the results (Karlovich, 1998).

More than $75 \%$ of seed testing laboratories now conduct one or more vigor tests. Every major seed company is acutely aware of the importance of seed vigor testing (McDonald, 1993). Commercial seed testing must be meaningful for the seed company as well as be run in a commercial seed lab working on a large scale (Galbreth, 1993). Members of the flower and vegetable seed industry, Ball Seed Company for example, are already using seed vigor to determine superior seed lots (Styer and Koranski, 1997). The tobacco seed industry is considering similar standards. Vigor testing is proving essential for value-added crops and high value seeds that are primed, pelleted, or coated prior to sale (Ferguson, 1993). Growers know that they are purchasing a viable seed lot, by the standard germination tests, and a vigorous seed lot, by the vigor tests (Styer and Koranski, 1997).

Because of the different methods in vigor testing, it is often difficult to compare the results of vigor tests between public and private laboratories, or even between private laboratories. Seed testing laboratories do not usually provide tests for seed vigor. Testing and recording germination across conditions that a seed lot will experience will determine seed uniformity and emergence under those varying conditions and therefore indicate seed vigor (Cantliffe, 2000). A dilemma of vigor testing often originates with communicating the vigor information. A seed lot may contain neither high nor low vigor seed, but may consist of a wide range of seed with varying degrees of vigor. High vigor may not necessarily guarantee high performance because of variation in environmental 
factors. The format of the vigor information must be presented with minimum standards in order for the customer to appreciate the information. Many have indicated that for a vigor test to be useful, it must have a high correlation coefficient with field performance. A more important aspect of vigor is the accuracy of the results because the correlation coefficient may be excellent, but the test results in the laboratory may be higher than the field emergence because of disease pressure for example. The coefficient of variability has been important to many seed companies. Because vigor information may not be reflective of seedling performance in the field or greenhouse, seedling evaluations can be performed to examine growth and uniformity that cannot be determined by vigor information. Seedling evaluations allow for quantitative measures of seed performance. Vigor information is useful and is able to aid in improving the overall quality of seed in the market place, but seedling evaluations can aid in determining how that seed performs (Berkey, 1993). Little research has been conducted to investigate tobacco seedling performance. A major explanation is the fact that tobacco seed is small and vigor testing is difficult, but seedling evaluations may be reliable descriptors of seed performance (T.D. Reed, personal communication, 2001). 


\section{References}

Association of Official Seed Analysts (AOSA). 1983. Seed vigor testing handbook. Contribution No. 32 to the Handbook of Seed Testing. Association of Official Seed Analysts 93pp.

Association of Official Seed Analysts (AOSA). 1992. Seedling evaluation handbook, Contribution No. 35 to the Handbook on Seed Testing. Association of Official Seed Analysts 101pp.

Berkey, D.A. 1993. Industry perspective of vigor testing. J. Seed Technol. 17: 127-133.

Bewley, J.D., and M. Black. 1994. Seeds: Physiology of development and germination. $2^{\text {nd }}$ ed. Plenum Press, New York.

Bunn, J.M., and W.E. Splinter. 1961. The effect of temperature, moisture, and light on the germination probability of bright leaf tobacco seed. Tob. Sci 5: 63-66.

Cantliffe, D. 2000. Understanding seed physiology from a grower's viewpoint. p. 94-102. In J. VanderVelde (ed.) GrowerTalks on Plugs 3. Ball Publ., Batavia, IL.

Cross, D., and R.C. Syter. 2000. Storing your seed the right way. p. 40-3. In J. VanderVelde (ed.) GrowerTalks on Plugs 3. Ball Publ., Batavia, IL.

Csinos A., and S. Ghate. 1982. Fluid sowing of pregerminated tobacco seed. Tob. Sci. 26:32-34.

Cundiff, J.S., A. Casinos, and S.C. Phatak. 1978. Variability in tobacco seedling growth related to day of emergence. Tob. Sci. 22:144-147.

Cundiff, J.S. 1979. Tobacco seed emergence related to differences in terminal velocity. Tob. Sci. 23:49-51.

Desai, B.B., P.M. Kotecha, and D.K. Salunkhe. 1997. Seeds handbook: Biology, production, processing, and storage. Marcel Dekker, New York.

Ferguson, J.M. 1993. AOSA perspective of seed vigor testing. J. Seed Technol. 17:101-04. 
Galbreth, A. 1993. Commercial vigor testing. J. Seed Technol. 17:101-04.

Gawande, M., S.C. Mohapatra, and W.H. Johnson. 1980. Effect of seed size and pelletization on tobacco seed germination under varying temperature regimes. Tob. Sci. 24:49-52.

Grabe, D.F. 1976. Measurement of seed vigor. J. Seed Technol. 1:18-32.

Gwyn, G.R. 1973. Effect of maturity on germination of seed of six tobacco cultivars. Tob. Sci. 17:108-109.

Hampton, J.G. 1993. The ISTA perspective of seed vigor testing. J. Seed Technol. 17:105-120.

Hopkins, M. 1996. A vision for vigor. Greenhouse Grower 14:36-39.

Hoyert, J.H. 1968. Germination (emergence) of tobacco seed and its relationship to total soluble salts as measured by electrical conductivity of the soil. Tob. Sci. 11:35-36.

Huthchens, T.W. 1999. Tobacco seed. p. 66-9. In D.L. Davis and M.T. Nielsen (ed.) Tobacco: Production, chemistry, and technology. Blackwell Science, London, UK.

Kahn, A.A. 1992. Preplant physiological conditioning treatments. Hortic. Rev. 13: $131-181$.

Karlovich, P.T. 1998. Flower seed testing and reporting needs of the professional grower. J. Seed Technol. 20:131-35.

Kasperbauer, M.J. 1968. Germination of tobacco seed: I. Inconsistency of light sensitivity. Tob. Sci. 12: 20-22.

Koroma, B.M., R.D. Keys, and R.P. Patterson. 1996. Genotype-related changes in stress protein synthesis induced by thermal stress during germination in Nicotiana tabacum. Tob. Sci. 40:29-36.

McDonald, M.B. 1993. The history of seed vigor testing. J. Seed Technol. 17:93-100. 
McDonald, M.B. 2000. Seed viability, germination, and vigor: Sorting out the terminology. p. 29-31. In J. VanderVelde (ed.) GrowerTalks on Plugs 3. Ball Publ., Batavia, IL.

McNertney, D. 1999. Visualizing the future: The Paradigm Seedlot Vigor Assessment System. p. 61-7. In A. Liptay, C.S. Vavrina, and G.E. Welbaum (ed.) Proc. Symp. Stand Establishment/Seed, Roanoke, VA. 15-19 May. 1999. Drukkerij Geers, Belgium.

Mohapatra, S.C. 1993. Genotypic variability in light requirements for germination of flue-cured tobacco seeds. Tob. Sci. 37:11-12.

Nichols, B.C., and R. L. Davis. 1965. Some management practices affecting the production of burley tobacco seed and the total value of the crop. Tob. Sci. 9:140-142.

Reed, T.D., J.L. Jones, C.S. Johnson, P.J. Semtner, and C.A. Wilkinson. 2001. 2001 Flue-cured tobacco production guide. Publ. 436-048. VA. Agric. Exp. Stn., Blacksburg, VA.

Scott, S.J., R.A. Jones, and W.A. Williams. 1984. Review of data analysis methods for seed germination. Crop Sci. 24:1192-99.

Shaw, J.A. 2000. The U.S. plug industry: Bigger plugs, better service. p. 1-6. In J. VanderVelde (ed.) GrowerTalks on Plugs 3. Ball Publ., Batavia, IL.

Smith, O.E., N.C. Welch, and T.M. Little. 1973. Studies on lettuce seed quality: I. Effect of seed size and weight on vigor. J. Am. Soc. Hortic. Sci. 98:529-33.

Styer, R.C. 2000. Improve your germination! p. 56-9. In J. VanderVelde (ed.) GrowerTalks on Plugs 3. Ball Publ., Batavia, IL.

Styer, R.C., and D.S. Koranski. 2000. Key tips for bench-top germination. p. 86-8. In J. VanderVelde (ed.) GrowerTalks on Plugs 3. Ball Publ., Batavia, IL.

Styer, R.C., and D.S. Koranski. 1997. Plug and transplant production: A grower's guide. Ball Publ., Batavia, IL.

TeKrony, D.M. 1982. Seed vigor testing-1982. J. Seed Technol. 8:55-61. 
Thomas, J.F., and C.D Raper, Jr,. 1975. Differences in progeny of tobacco due to the temperature of the mother plant. Tob. Sci. 19:37-40.

Thomas, J.F., and C.D., Jr Raper. 1979. Germinability of tobacco seed as affected by culture of the mother plant. Agron. J. 71:694-5.

Tso, T.C. 1990. Production, physiology, and biochemistry of tobacco plant. Ideals, Beltsville, MD.

Welbaum, G.E., Z. Shen, M.O. Oluoch, and L.W. Jett. 1998. The evolution and effects of priming vegetable seeds. Seed Technol. 20:209-35. 


\title{
Chapter III.
}

\section{Development of a Greenhouse Tobacco Seedling Performance Index}

\author{
Abstract \\ Greenhouse transplant production has replaced outdoor plant beds over the \\ last decade resulting in increased importance of tobacco seed quality. \\ Commercial tobacco seed lots often fail to achieve stands that reflect the certified \\ germination percentage under variable greenhouse conditions. No method \\ currently exists to describe tobacco seedling performance under greenhouse \\ conditions. This study was conducted to develop a seedling performance index \\ (SPI) to describe differences in greenhouse tobacco seedling performance. The \\ SPI was based on a scale of 0 to100 using 14-d emergence, relative leaf area \\ uniformity, and seedling leaf area determined by computerized image analysis. \\ Although all seed lots evaluated had a certified $90 \%$ germination, significant \\ differences in the SPI among seed lots were observed. Seed lots with a lower \\ spiral root incidence and more rapid germination rate had a significantly higher \\ SPI. The SPI quantified differences in seed lots not reflected by standard \\ germination or vigor tests. The simplicity of SPI is reflected in data collection. \\ The SPI only requires one seed tray image because all the data needed to calculate \\ the SPI could be determined from that image. In contrast, most germination and \\ vigor tests require repeated counts and seedling evaluations.
}




\section{Introduction}

Tobacco seed quality has been given greater attention as greenhouse transplant production has replaced outdoor plant beds over the last decade. Variability associated with tobacco seed emergence has become an important issue with greenhouse producers because of the reduced overproduction of transplants. High emergence and rapid, uniform growth are essential to successful transplant production. Tobacco seed is purchased with a certified $90 \%$ germination, which is determined by seed companies under optimal conditions.

Standard germination tests are performed on tobacco seed under controlled laboratory conditions using wet blotter paper as the medium (AOSA, 1999). These controlled conditions differ greatly from fluctuating greenhouse conditions, so germination may differ notably in the greenhouse. The laboratory germination test establishes maximum plant-producing potential of a seed lot under ideal conditions. Standard germination tests confirm viability, but are not useful for predicting vigor or seedling performance in the greenhouse (AOSA, 1992). Germination rate describes the speed at which seeds in a population produce a radicle but reveals nothing about the uniformity or the size of emerging seedlings after germination period is complete and seedling growth begins.

Vigor testing and seedling evaluations are two methods that seed companies use to provide information, in addition to germination data, about seed lots. The Association of Official Seed Analysts (AOSA) (1983) defines seed vigor as the sum total of all those properties in seed which, upon planting, result in rapid and uniform production of healthy seedlings under a wide range of environments, including unfavorable and stressful conditions. Vigor testing often examines seed under adverse conditions, such as temperature extremes, but requires that the variable of interest be the only condition changing.

Digital imaging technology has been applied to vigor tests. Ball Seed Company (Batavia, Illinois), a leading flower seed producer, patented the Ball 
Vigor Index, which uses computer image analysis to evaluate seed vigor based on cotyledon expansion (Ball Seed Company, 2000). Paradigm Research Corporation (South Haven, Minnesota) developed the Seed Vigor Assessment System, which utilizes imaging technology to measure total root length of seedlings in a petri dish (McNertney, 1999). F.W. Rickard Seeds (Winchester, Kentucky) has produced commercial tobacco seed since 1937. They examined the Paradigm's Seed Vigor Assessment System in the spring of 2000 and found the procedure not applicable to testing tobacco seedling performance under greenhouse conditions (T. Hutchens, personal communication, 2000). Neither vigor nor germination percentage as determined in the laboratory fully characterizes seedling performance in the field or greenhouse environment.

Seedling evaluations made several days into plants development may more accurately describe variation in seedlings and seedling performance. Evaluations conducted during standard germination testing classify seedlings for defects that will impair continued development of the seedling. Plant structures evaluated for normalcy are cotyledon(s), root system, hypocotyl, epicotyl, terminal bud, and primary leaves (AOSA, 1992). Spiral roots are a common abnormality in tobacco greenhouses. A spiral rooted tobacco seedling occurs when the growing point of the emerging root tip is damaged and the seedling fails to develop properly (R.C. Pearce, personal communication, 2001). The result is a root that does not initially penetrate into the growing media, but secondary roots may develop and normal seedling growth resumes, although delayed. Spiral roots directly affect seedling performance and uniformity because these abnormal seedlings may not survive or may survive but be smaller and unsuitable for transplanting (Reed et al., 2001). Tobacco seedling evaluations during stand counts indicate the frequency of abnormal seedlings associated with spiral roots.

Leaf area and uniformity of the seedlings also affect tobacco seedling performance in the greenhouse. A small tobacco seedling is much more likely to 
be injured or killed by high fertilizer concentrations in outdoor plant beds (Hoyert, 1968). No method currently exists to measure area and uniformity of cotyledons and primary leaves that would describe seedling performance in the greenhouse. The need for a method, other than germination percentages, to objectively describe seedling performance is critical. A method to measure seedling performance based on emergence, size, and uniformity would allow a quantitative description of the amount of variation that occurs in tobacco seedlings. The objective of this study was to develop a greenhouse tobacco seedling performance index using emergence, germination rate, and leaf area measured by computer image analysis. The index was used to assess the variation associated with commercially available seed lots.

\section{Materials and Methods}

\section{Data collection}

Trials were conducted in a greenhouse at Southern Piedmont Agricultural Research and Extension Center (SPAREC) and in grower greenhouses in Mecklenburg (Clary) and Brunswick (Harrison and Lynch) counties. Either 288or 338-cell styrofoam float trays (Radva, Radford, VA) were used in each trial. Trays were filled with Carolina Choice (Carolina Soil Company, Kinston, NC), a commercial soilless medium commonly used in float system operations. Float trays were seeded using a Berry (Elizabeth City, NC) rolling seeder. A Berry automatic tray-filling box was used to fill the trays and a half-tray drop seeder (Carolina Soil Company, Kinston, NC) was used to seed trays at SPAREC. The experimental design for each trial was a randomized complete block with four or six replications. A replication consisted of either a whole or half-tray of each treatment. Trays were placed in the center of the greenhouses to minimize temperature differentials observed between the center and outside edges. 
One trial each at SPAREC, Clary, and Harrision examined the effect of four seed enhancements (A-D) on one seed lot of flue-cured tobacco cultivar NC 72. Seed enhancement A was the control and was treated the same as other commercially available seed lots. The Clary, Harrison, and SPAREC seed enhancement trials were seeded in February and March 2001. Two additional trials at SPAREC and Lynch examined differences in four seed lots each of fluecured cultivars NC 297 and NC 71, respectively. The seed lot trials at Lynch and SPAREC were seeded in March 2000 and January 2001, respectively.

The number of seedlings emerged were counted on $7,8,9,10,12$, and 14 $\mathrm{d}$ after seeding. Emergence is defined as cotyledon expansion from the pellet. Spiral roots were counted on 12 and $14 \mathrm{~d}$ after seeding. All counts were performed on a 72-cell subsample of seedlings from the tray. One image was taken of each tray in each trial at $14 \mathrm{~d}$ after seeding (Figure 3.1). Images were taken with a CoolPix 950 (Nikon, Richmond, VA) digital camera at a resolution of 1024 x 840 pixels. A UV lens filter was used under excessive light intensity conditions, whereas a $25 \%$ light reducing lens filter was used when the quantity of light interfered with image quality. The float-tray was placed in wooden box beneath the camera mounted on a tripod (Figure 3.2). Seedlings analyzed for leaf area data were selected from a subsample of the entire tray. The first fifty seedlings of approximately 130 cells captured on an image were individually selected for leaf area analysis. Cells with missing seedlings or seedlings not projecting a horizontal surface, such as those emerging in the corner of a cell, were not used for leaf area analysis. The leaf area data obtained from digital analysis was saved in a Microsoft Excel file.

The images were analyzed using WinRHIZO (Ver. 4.1Pro) developed by Regent Instruments, Quebec, Quebec, which measures the apparent horizontal area of the cotyledons and the first true leaves present at $14 \mathrm{~d}$ after seeding using color classes. The color classes by which the image was analyzed were selected 
from the image itself (Figure 3.3). Calibrating the software is required and was performed using the pixels over a short width and height of an image in the test of interest (Figure 3.4). The single calibration would suffice for the other images in the test. The leaf area data was collected as pixels per unit area.

\section{Greenhouse Tobacco Seedling Performance Index (SPI)}

Components of seedling performance include rapid and uniform emergence. Emergence can be counted manually from digital images or actual trays. Leaf area of tobacco seedlings in the greenhouse float-tray can be measured using digital analysis. The coefficient of variation $(\mathrm{CV})$ can be utilized as a measure of relative seedling uniformity. The $\mathrm{CV}$ expresses the standard deviation per experimental unit as a percent of the general mean of the experiment (Little and Hills, 1978). A larger CV is indicative of a nonuniform seedling population. The variability among experimental units involving different units of measurement or plot sizes can be compared using the CV (Little and Hills, 1978). Csinos and Ghate (1982) detected differences in plant height using the CV in a study involving fluid sowing of pregerminated tobacco seed.

The greenhouse tobacco seedling performance index is calculated as:

$$
\mathrm{SPI}=[(0.50 \times \mathrm{E})+(0.20 \times \mathrm{S})+(0.30 \times \mathrm{U})] \times 100
$$

where:

$$
\begin{aligned}
& \text { Emergence }(E)=14-d \text { stand count } \\
& \text { Size }(S)=\frac{\text { mean leaf area } a_{i}}{1100}
\end{aligned}
$$

and,

$$
\text { Uniformity }(\mathrm{U})=1-\mathrm{CV} \text {. }
$$

The mean leaf area $\mathrm{i}_{\mathrm{i}}$ is the mean leaf area of the image of interest in a trial. The value 1100 is a constant determined by examining the mean leaf areas of approximately 100 seed lots. This value reflects an upper limit for leaf area of 
tobacco seedlings at $14 \mathrm{~d}$ after seeding. If mean leaf area $\mathrm{i}_{\mathrm{i}}$ exceeds 1100 , then $\mathrm{S}=$ 1. The coefficient of variation $(\mathrm{CV})$ of leaf area is described as $\mathrm{CV}=(\mathrm{s} / \mathrm{x})$, where $\mathrm{s}$ and $\mathrm{x}$ are the standard deviation and mean of the 50 selected seedlings, respectively. The weighting factors of 0.30 for emergence, 0.50 for uniformity, and 0.20 for size allow the SPI to be based on a 0 to 100 scale, since the maximum values for $\mathrm{E}, \mathrm{S}$, and $\mathrm{U}$ are each one.

The germination rate and the germination index (GI) (Scott et al., 1984) were calculated for all seed lot trials. Trials at the Lynch and SPAREC greenhouses used Seed Calculator (Ver. 2.2) developed by Plant Research International, Wageningen, The Netherlands, to calculate the mean time to germination (T50) and the time between $10 \%$ and $90 \%$ of the maximum germination achieved (U10-90). Probit analysis was performed using SigmaPlot (2000, SPSS, Chicago, Illinois), to determine the T50 for seed lot trials where count data was inappropriate to use Seed Calculator. Germination counts between sequential days cannot increase more than $20 \%$ for use of Seed Calculator.

The germination index is calculated as: $\mathrm{GI}=\sum \mathrm{T}_{\underline{i}} \underline{\underline{x}}-\underline{\mathrm{N}_{\mathrm{i}}}$, $\mathrm{S}$ where $T_{i}$ is the number of days after sowing, $N_{i}$ is the number of seeds germinated on day $\mathrm{i}$, and $\mathrm{S}$ is the total number of seeds sown.

An analysis of variance was performed using PROC ANOVA in SAS for the seed lot trials at Clary, Harrison, Lynch, and SPAREC (SAS Institute, 2000). Comparison of the control A to the seed treatments (B-D) for Clary, Harrison, and SPAREC seed treatment trials was made using the Dunnett's test. Treatment means for the Lynch and SPAREC seed lot trials were separated with Fischer's Least Significant Difference test (SAS Institute, 2000).

\section{Results and Discussion}

The weighting factors for $\mathrm{E}(0.30), \mathrm{S}(0.20)$, and $\mathrm{U}(0.50)$ were chosen based on relative importance. Uniformity was chosen as the most important 
parameter of seedling performance based on results obtained from varying the weighting factors of $\mathrm{E}, \mathrm{S}$, and $\mathrm{U}$ and evaluating the results (Tables 3.1, 3.2, and 3.3). Tobacco seed is purchased with a certified $90 \%$ germination, so emergence should not vary among seed lots as much as uniformity or size. Emergence was weighted more heavily than size because achieving a desired stand is critical. Size was given the lowest weighting because earlier emerging seed lots, such as primed seed lots are often larger based on their early emergence. Late emerging seed lots with high 14-d emergence and increased uniformity would be penalized if size had increased weighting. Spiral roots were accounted for in the uniformity and size components. All spiral rooted seedlings do not die, but may survive, so a seedling being spiral rooted is of lesser concern than the impact that spiral rooted seedlings have on size and uniformity.

NC 72 Seed Enhancement Trial. No significant differences in emergence were observed for seed enhancements (B-D) compared to control A in the Clary, Harrison, or SPAREC trials (Tables 3.4, 3.5, and 3.6). Emergence was marginal for all seed enhancements in the Clary trial, with seed enhancement D never reaching $90 \%$ emergence. There were no significant differences in spiral root incidence for seed enhancements (B-D) compared to control A at the Harrison and SPAREC trials. Seed enhancements C and D had significantly lower spiral root incidence than the control A at the Clary trial. Emergence and spiral root incidence were similar at Harrison and SPAREC greenhouses, but both emergence and spiral root incidence were lower at the Clary greenhouse.

The T50 value for seed enhancement $\mathrm{D}$ was significantly lower than $\mathrm{A}$ at the Clary and SPAREC greenhouses, which indicated earlier emergence. In contrast, T50 values for seed enhancements B and C were significantly higher than the control A at the Harrison greenhouse, which indicated later emergence. The GI was significantly lower for the seed enhancements C and D at the Clary and SPAREC trial, but no significant differences existed in the GI for the seed 
treatments at the Harrison trial. At the SPAREC greenhouse, the U90-10 value for seed enhancement B was significantly higher than the control A, which indicated prolonged, nonuniform emergence, and the U90-10 value for seed enhancement D was significantly lower than the control A, which indicated rapid, uniform emergence.

There were no significant differences in the SPI for seed enhancements (B-D) compared to control A at the Clary trial in part due to the low emergence of seed enhancements. Seed enhancement $\mathrm{C}$ had a higher SPI compared to seed enhancement A at the SPAREC and Clary greenhouses, but the difference was significant only at SPAREC. There was no significant difference between seed enhancements $\mathrm{A}$ and $\mathrm{C}$ at the Harrison greenhouse. The increased spiral root incidence and slower germination rate lowered the SPI of seed enhancements A and $\mathrm{B}$ at the Clary and SPAREC greenhouses. Despite having quicker, early emergence, the low 14-d emergence and overall nonuniform seedling growth of seed enhancements $\mathrm{C}$ and D contributed to a higher, but not significantly different SPI at the Clary trial. Seed enhancement A had high emergence and a lower T50 that indicated earlier emergence at the Harrison greenhouse that resulted in a high SPI, despite having a high spiral root incidence. Early emergence allows for more seedling growth to occur by $14 \mathrm{~d}$ after seeding, as opposed to seedlings emerging later, and results in larger seedlings overall.

Regardless of having reached $50 \%$ of maximum germination more quickly than seed enhancement A, seed enhancement B took longer once $10 \%$ of maximum germination was reached to acquire $90 \%$ of maximum germination at SPAREC. This indicated quicker early emergence and then prolonged emergence that continued for days and resulted in a nonuniform seedling population. The lack of uniformity for seed enhancement B lowered its SPI. A smaller U90-10, T50, and decreased spiral root incidence created a more uniform population of 
seedlings for seed enhancement $\mathrm{C}$ that resulted in a SPI that was significantly higher than seed enhancement A at SPAREC.

NC 71 Seed Lot Trial. Seed lot 2 had a significantly lower emergence than the other three seed lots at the Lynch greenhouse (Table 3.7). Seed lots 1 and 4 had significantly greater spiral root incidence than seed lots 2 and 3, and seed lot 2 had significantly greater spiral root incidence than seed lot 3 . Seed lot 3 had a significantly lower GI than the other three seed lots. The lower GI of seed lot 3 indicated that emergence occurred over a shorter time period, which was also demonstrated by lower U90-10 and T50 values. The T50 and U90-10 values for seed lots 3 and 4 were significantly lower than seed lot 1, which indicated a slower germination rate for seed lot 1 . In addition to having reached $50 \%$ of maximum germination more quickly, seed lots 3 and 4 took less time once $10 \%$ of maximum germination was reached to acquire $90 \%$ of maximum germination. The increased uniformity because of germination occurring over a shorter time period and early seedling growth contributed to a SPI for seed lot 3 that was significantly higher than the other three seed lots. Although seed lot 4 had a quicker germination rate, increased spiral root incidence created a nonuniform population that lowered the SPI, so that it was not significantly different from seed lot 1 . Seed lot 2 had a significantly lower SPI than the other three seed lots. The lower, prolonged emergence combined with increased spiral root incidence of seed lot 2 contributed greatly to reducing the SPI.

NC 297 Seed Lot Trial. Seed lot 4 had a significantly lower emergence than seed lots 1 and 3, but was not significantly lower than seed lot 2 (Table 3.8). Seed lots 2 and 3 had significantly greater spiral root incidence than seed lots 1 and 4 . Seed lots 1 and 4 had a significantly higher GI than seed lots 2 and 3, and seed lot 3 had a significantly lower GI than seed lot 2. A lower GI indicates that emergence was occurring over a shorter time period, so a more uniform population may result. Seed lot 4 had a significantly higher T50 than the other 
three seed lots, which described a delayed and slow germination rate. The T50 value for seed lot 3 was significantly lower than seed lots 1 and 2, which described an early, rapid germination rate. The U90-10 value for seed lots 1, 3, and 4 was significantly lower than seed lot 2 . In spite of seed lot 4 having delayed emergence, once $10 \%$ of maximum germination was reached, only slightly more than a day was taken to acquire $90 \%$ of maximum germination. Seed lot 4 had a uniform population because of the short germination period, but because of the delayed beginning of germination, seedlings were small and the SPI was significantly lower than the other three seed lots. Seed lot 2 took significantly more time to obtain $90 \%$ emergence after $10 \%$ emergence had been obtained than seed lot 1, so despite having similar T50 values, seed lot 2 had a significantly lower SPI than seed lots 1 and 3. Despite having a higher spiral root incidence, the high, early, and uniform emergence and rapid growth of seed lot 3 contributed to a significantly higher SPI than the other three seed lots.

Summary. Seed trials indicated that $14 \mathrm{~d}$ after seeding is the most appropriate time for image analysis of seedling performance. At $14 \mathrm{~d}$ after seeding, the greenhouse tobacco seedling performance index adheres with the maximum commercially accepted length of time germination should be occurring for tobacco (AOSA, 1999). If measured before $14 \mathrm{~d}$, plants germinating on the fourteenth day would be eliminated from leaf area analysis, but counted for emergence, resulting in a misrepresentation of that seed lot. Beyond $14 \mathrm{~d}$, the seedlings rely on photosynthesis and their root system grows rapidly. Digital analysis is made difficult with overlapping leaves. Images taken at $14 \mathrm{~d}$ after seeding did show differences in size and uniformity that resulted in differences in the SPI.

Emergence is important for establishing a plant stand. Uniformity and size describe the quality of that plant stand. Uniform transplants are an advantage of greenhouse production, but lack of uniformity makes greenhouse management 
of transplants difficult. Early, rapid seedling growth is desirable to avoid potential fertilizer salts injury that may occur with the natural accumulation of salts deposited near the medium surface as a result of evaporation. Poor emergence cannot be corrected in greenhouse tobacco transplant production.

A clipping routine that begins approximately $30 \mathrm{~d}$ after seeding regulates growth and allows small seedlings to reach the size of the larger seedlings, creating a more uniform plant population. Early growth cannot be controlled, but differences detected could help producers more effectively manage nonuniform plant stands. Uniformity is weighted more heavily than size because a uniform small population can be managed more effectively than a large nonuniform population. A nonuniform population has smaller seedlings that may be sacrificed to fertilizer salt injury because the larger plants need the fertilizer to maintain an acceptable growth rate.

Using germination rate as a seedling performance descriptor does not account for abnormal seedlings, such as spiral roots. Spiral roots are a common seedling abnormality that may reduce plant stand beyond $14 \mathrm{~d}$, but impact uniformity and seedling size at $14 \mathrm{~d}$. Size and uniformity differences at $14 \mathrm{~d}$ effect subsequent growth and uniformity of transplants. Spiral root seedlings are accounted for using the SPI. The effect of delayed emergence on seedling growth and uniformity can be measured using the SPI.

The SPI provides a simple method by which to measure tobacco seedling performance under greenhouse conditions. A high viability seed lot may not perform well under varied greenhouse conditions. Significant differences were observed in the SPI of an original seed lot with different seed treatments and different seed lots within a cultivar (Tables 3.4 to 3.9). The SPI accounts for time of germination (germination rate), final germination, seedling size and uniformity, and spiral root seedling occurrence. The SPI is based on a scale of 0 to 100 . A higher SPI indicates a better performing seed lot (Figure 3.5), which is 
demonstrated by higher emergence, greater seedling leaf area, and greater uniformity. A lower SPI indicates a poor performing seed lot (Figure 3.6) that may not be indicative of lower emergence, but may have a smaller seedling leaf area and less uniformity. Seed lots in Figures 3.5 and 3.6 have identical 14-d emergence, so in a standard seed germination test, the seed lots would be rated equal, despite the large difference in seedling size and uniformity. The SPI allows the differences in size and uniformity to more accurately describe the seed lot. The SPI of a seed lot may change with test conditions, so the index can be used to reflect how seed lots perform under varied environmental conditions and may be used as a research tool to evaluate media, fertilization, or other production variables.

The results of this study indicate that leaf area analysis and emergence can determine differences in the performance of seed lots. The method used to acquire the images proved effective in obtaining quality images. The SPI requires fewer counts to be done in order to determine how a seed lot performs. Seed Calculator effectively measured seed vigor, but it requires frequent counting, as does the GI. The GI is indicative of rate, because it describes the time period that germination is completed, but fails to account for actual emergence because a seed lot with $90 \%$ germination can have the same GI as a seed lot with $98 \%$ germination. The SPI of a seed lot can be calculated from a single 14-d image. Emergence data can be measured directly from the image along with leaf area, making the SPI more efficient than performing a dozen counts, which may be needed to accurately calculate the germination rate. Results indicated that differences could be detected in the SPI of seed lots with equal 14-d emergence that may not be detected by germination rate. 


\section{Acknowledgements}

We thank Carolina Soil Company, Kinston, North Carolina for providing the media and the half-tray seeder used to conduct the seed trials. We also extend our gratitude to F.W. Rickard Seeds, Winchester, Kentucky, and Gold Leaf Seed Company, Hartsville, South Carolina, for providing the seed lots used in the research. 


\section{References}

Association of Official Seed Analysts (AOSA). 1983. Seed vigor testing handbook, Contribution No. 32 to the Handbook on Seed Testing. Association of Official Seed Analysts 93pp.

Association of Official Seed Analysts (AOSA). 1992. Seedling evaluation handbook, Contribution No. 35 to the Handbook on Seed Testing. Association of Official Seed Analysts 101pp.

Association of Official Seed Analysts (AOSA). 1999. Rules for testing seeds. Association of Official Seed Analysts (AOSA). Lincoln, NE.

Ball Seed Company. 2000. Ball Vigor Index. [Online]. Available at http://www.ballseed.com/BallPremierA_page.htm (verified 1 February 2001).

Csinos A., and S. Ghate. 1982. Fluid sowing of pregerminated tobacco seed. Tob. Sci. 26:32-34.

Cundiff, J.S., A. Casinos, and S.C. Phatak. 1978. Variability in tobacco seedling growth related to day of emergence. Tob. Sci. 22:144-147.

Hoyert, J.H. 1968. Germination (emergence) of tobacco seed and its relationship to total soluble salts as measure by electrical conductivity of the soil. Tob. Sci. 11:35-36.

Little, T.M., and F.J. Hills. 1978. Agricultural experimentation: Design and analysis. John Wiley \& Sons, New York.

McNertney, D. 1999. Visualizing the future: The Paradigm Seedlot Vigor Assessment System. p. 61-7. In A. Liptay, C.S. Vavrina, and G.E. Welbaum (ed.) Proc. Int. Symp. Stand Establishment/Seed, Roanoke, VA. 15-19 May. 1999. Drukkerij Geers, Belgium.

Reed, T.D., J.L. Jones, C.S. Johnson, P.J. Semtner, and C.A. Wilkinson. 2001. 2001 Flue-cured tobacco production guide. Pub 436-048. VA Agric. Exp. Stn., Blacksburg, VA.

Regent Instruments, Inc. 2000. WinRHIZO. Release 4.1Pro. Regent Instruments, Inc., Quebec, Canada. 
SAS Institute. 2000. The SAS system for Windows. Release 8.0. SAS Inst., Cary, NC.

Scott, S.J., R.A. Jones, and W.A. Williams. 1984. Review of data analysis methods for seed germination. Crop Sci. 24:1192-99. 
Table 3.1. Influence of weighting factors on the seedling performance index (SPI) using one seed lot of flue-cured tobacco cultivar NC 72 with four seed enhancements, Clary greenhouse, Mecklenburg County, Virginia.

\begin{tabular}{|c|c|c|c|c|c|c|c|c|}
\hline Treatment & $\mathrm{E}^{1}$ & $S$ & $\mathrm{U}$ & $\begin{array}{c}1 / 3{ }^{1} / 3^{1 / 3} \\
\text { SPI }\end{array}$ & 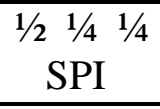 & 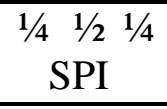 & 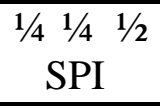 & $\begin{array}{c}3 / 10^{2} / 105 / 10 \\
\text { SPI }\end{array}$ \\
\hline A & 0.929 & 0.472 & 0.612 & 67.1 & 73.6 & 62.1 & 65.6 & 67.9 \\
\hline B & 0.910 & 0.521 & 0.578 & 67.0 & 73.0 & 63.3 & 64.7 & 66.6 \\
\hline $\mathrm{C}$ & 0.917 & $0.601^{*}$ & 0.631 & $71.6^{*}$ & 76.6 & $68.7^{*}$ & 69.5 & 71.1 \\
\hline $\mathrm{D}$ & 0.888 & $0.612^{*}$ & 0.644 & $71.5^{*}$ & 75.8 & $68.9^{*}$ & 69.7 & 71.1 \\
\hline
\end{tabular}

* Means are significantly different from A at 0.05 probability levels based on a Dunnett's test.

${ }^{1} \mathrm{E}=$ emergence, $\mathrm{S}=$ Seedling size, $\mathrm{U}=$ Uniformity. Numbers above SPI represent weighting of E, S, and U, respectively. 
Table 3.2. Influence of weighting factors on the seedling performance index (SPI) using one seed lot of flue-cured tobacco cultivar NC 72 with four seed enhancements, Harrison greenhouse, Brunswick County, Virginia.

\begin{tabular}{|c|c|c|c|c|c|c|c|c|}
\hline Treatment & $E^{1}$ & $\mathrm{~S}$ & $\mathrm{U}$ & $\begin{array}{c}1 / 3{ }^{1} / 3^{1 / 3} \\
\text { SPI } \\
\end{array}$ & $\begin{array}{c}1 / 21 / 41 / 4 \\
\text { SPI }\end{array}$ & $\begin{array}{c}1 / 4 \quad 1 / 2 \quad 1 / 4 \\
\text { SPI }\end{array}$ & $\begin{array}{c}1 / 4 \quad 1 / 4 \quad 1 / 2 \\
\text { SPI }\end{array}$ & $\begin{array}{c}3 / 10^{2} / 105 / 10 \\
\text { SPI }\end{array}$ \\
\hline A & 0.968 & 1.000 & 0.728 & 89.9 & 91.6 & 92.4 & 85.6 & 85.5 \\
\hline B & 0.948 & $0.621^{*}$ & $0.557^{*}$ & $70.9^{*}$ & $76.9^{*}$ & $68.7^{*}$ & $67.1^{*}$ & $68.8^{*}$ \\
\hline $\mathrm{C}$ & 0.962 & 1.000 & 0.715 & 89.2 & 90.9 & 91.9 & 84.8 & 84.6 \\
\hline D & 0.916 & $0.525^{*}$ & $0.548^{*}$ & $66.3^{*}$ & $72.7^{*}$ & $62.9^{*}$ & $63.4^{*}$ & $65.4^{*}$ \\
\hline
\end{tabular}

* Means are significantly different from A at 0.05 probability levels based on a Dunnett's test.

${ }^{1} \mathrm{E}=$ emergence, $\mathrm{S}=$ Seedling size, $\mathrm{U}=$ Uniformity. Numbers above SPI represent weighting of E, $\mathrm{S}$, and $\mathrm{U}$, respectively. 
Table 3.3 Influence of weighting factors on the seedling performance index (SPI) using one seed lot of flue-cured tobacco cultivar NC 72 with four seed enhancements, SPAREC greenhouse, Nottoway County, Virginia.

\begin{tabular}{|c|c|c|c|c|c|c|c|c|}
\hline Treatment & $\mathrm{E}^{1}$ & $\mathrm{~S}$ & $\mathrm{U}$ & $\begin{array}{c}1 / 3{ }^{1} 1 / 31 / 3 \\
\text { SPI }\end{array}$ & $\begin{array}{c}1 / 2 \quad 1 / 4 \quad 1 / 4 \\
\text { SPI }\end{array}$ & $\begin{array}{c}1 / 4 \quad 1 / 21 / 4 \\
\text { SPI }\end{array}$ & $\begin{array}{c}1 / 4 \quad 1 / 4 \quad 1 / 2 \\
\text { SPI }\end{array}$ & $\begin{array}{c}3 / 102 / 105 / 10 \\
\text { SPI }\end{array}$ \\
\hline A & 0.965 & 0.655 & 0.609 & 74.3 & 79.9 & 72.1 & 71.0 & 71.0 \\
\hline B & 0.958 & $0.746^{*}$ & 0.600 & 76.8 & 81.6 & $76.3^{*}$ & 72.6 & 71.9 \\
\hline $\mathrm{C}$ & 0.961 & $1.000^{*}$ & 0.630 & $86.4^{*}$ & $88.8^{*}$ & $89.8^{*}$ & $80.6^{*}$ & $78.3^{*}$ \\
\hline D & 0.949 & $0.973^{*}$ & 0.621 & $84.8^{*}$ & $87.3^{*}$ & $87.9^{*}$ & $79.1^{*}$ & $77.2^{*}$ \\
\hline
\end{tabular}

* Means are significantly different from A at 0.05 probability levels based on a Dunnett's test.

${ }^{1} \mathrm{E}=$ emergence, $\mathrm{S}=$ Seedling size, $\mathrm{U}=$ Uniformity. Numbers above SPI represent weighting of E, $\mathrm{S}$, and $\mathrm{U}$, respectively. 
Table 3.4. Seedling performance data for one seed lot of flue-cured tobacco cultivar NC 72 with four seed enhancements, Clary greenhouse, Mecklenburg County, Virginia.

\begin{tabular}{|c|c|c|c|c|c|}
\hline \multirow[b]{2}{*}{ Treatment } & \multicolumn{2}{|c|}{$14-\mathrm{d}$} & \multirow[b]{2}{*}{$\mathrm{T} 50$} & \multirow[b]{2}{*}{ GI } & \multirow[b]{2}{*}{ SPI } \\
\hline & Emerg. & Sp. Roots & & & \\
\hline & \multicolumn{2}{|c|}{ — Percentage -} & - & - & \\
\hline A & 92.9 & 21.8 & 8.5 & 8.7 & 67.9 \\
\hline B & 91.0 & 23.7 & 8.5 & 8.2 & 66.6 \\
\hline C & 91.7 & $12.2^{*}$ & 8.2 & $7.6^{*}$ & 71.1 \\
\hline D & 88.8 & $12.2^{*}$ & $7.7^{*}$ & $7.4^{*}$ & 71.1 \\
\hline
\end{tabular}

* Means are significantly different from A at 0.05 probability levels based on a Dunnett's test. 
Table 3.5. Seedling performance data for one seed lot of flue-cured tobacco cultivar NC 72 with four seed enhancements, Harrison greenhouse, Brunswick County, Virginia.

\begin{tabular}{|c|c|c|c|c|c|}
\hline \multirow[b]{2}{*}{ Treatment } & \multicolumn{2}{|c|}{$14-d$} & \multirow[b]{2}{*}{$\mathrm{T} 50$} & \multirow[b]{2}{*}{ GI } & \multirow[b]{2}{*}{ SPI } \\
\hline & Emerg. & Sp. Roots & & & \\
\hline & \multicolumn{2}{|c|}{ - Percentage } & - & 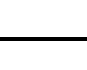 & \\
\hline A & 96.8 & 32.1 & 7.7 & 8.3 & 85.5 \\
\hline B & 94.8 & 30.1 & $9.1^{*}$ & 8.6 & $68.8^{*}$ \\
\hline $\mathrm{C}$ & 96.2 & $8.3^{*}$ & $8.5^{*}$ & 8.1 & 84.6 \\
\hline D & 91.6 & $4.8^{*}$ & 7.8 & 8.3 & $65.4^{*}$ \\
\hline
\end{tabular}

* Means are significantly different from A at 0.05 probability levels based on a Dunnett's test. 
Table 3.6. Seedling performance data for one seed lot of flue-cured tobacco cultivar NC 72 with four seed enhancements, SPAREC greenhouse, Nottoway County, Virginia.

\begin{tabular}{cccccccc}
\hline & \multicolumn{2}{c}{ 14-d } & & & \\
Treatment & Emerg. & Sp. Roots & & T50 & U90-10 & GI & SPI \\
\cline { 2 - 3 } A & 96.5 & 22.0 & 6.9 & 1.9 & 7.2 & 71.0 \\
B & 96.5 & 23.8 & $6.7^{*}$ & $2.1^{*}$ & 7.0 & 71.9 \\
C & 96.1 & 16.0 & $6.2^{*}$ & 1.8 & $6.6^{*}$ & $78.3^{*}$ \\
D & 94.9 & 19.9 & $6.1^{*}$ & $1.7^{*}$ & $6.4^{*}$ & $77.2^{*}$ \\
\hline
\end{tabular}

* Means are significantly different from A at 0.05 probability levels based on a Dunnett's test. 
Table 3.7. Seedling performance data for four seed lots of flue-cured tobacco cultivar NC 71, Lynch greenhouse, Brunswick County, Virginia.

\begin{tabular}{|c|c|c|c|c|c|c|}
\hline \multirow[b]{2}{*}{ Seed lot } & \multicolumn{2}{|c|}{$14-d$} & \multirow[b]{2}{*}{$\mathrm{T} 50$} & \multirow[b]{2}{*}{ U90-10 } & \multirow[b]{2}{*}{ GI } & \multirow[b]{2}{*}{ SPI } \\
\hline & Emerg. & Sp. Roots & & & & \\
\hline & \multicolumn{2}{|c|}{$\longrightarrow$ Percentage } & 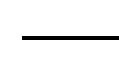 & Days & - & \\
\hline 1 & $95.8 \mathrm{a}^{\dagger}$ & $17.3 \mathrm{a}$ & $8.0 \mathrm{a}$ & $2.3 \mathrm{a}$ & $5.8 \mathrm{~b}$ & $74.2 \mathrm{bc}$ \\
\hline 2 & $83.7 \mathrm{~b}$ & $9.6 \mathrm{~b}$ & $7.8 \mathrm{a}$ & $2.0 \mathrm{ab}$ & $5.9 \mathrm{~b}$ & $61.8 \mathrm{~d}$ \\
\hline 3 & 96.8 a & $4.2 \mathrm{c}$ & $7.1 \mathrm{~b}$ & $1.1 \mathrm{~b}$ & $5.0 \mathrm{a}$ & $88.6 \mathrm{a}$ \\
\hline 4 & $96.2 \mathrm{a}$ & $15.4 \mathrm{a}$ & $7.4 \mathrm{~b}$ & $1.1 \mathrm{~b}$ & $5.8 \mathrm{~b}$ & $73.3 \mathrm{bc}$ \\
\hline
\end{tabular}

${ }^{\dagger}$ Means within a column followed by the same letter are not significantly different based on $\operatorname{LSD}(P=0.05)$. 
Table 3.8. Seedling performance data for four seed lots of flue-cured tobacco cultivar NC 297, SPAREC greenhouse, Nottoway County, Virginia.

\begin{tabular}{|c|c|c|c|c|c|c|}
\hline \multirow[b]{2}{*}{ Seed lot } & \multicolumn{2}{|c|}{$14-d$} & \multirow[b]{2}{*}{$\mathrm{T} 50$} & \multirow[b]{2}{*}{ U90-10 } & \multirow[b]{2}{*}{ GI } & \multirow[b]{2}{*}{ SPI } \\
\hline & Emerg. & Sp. Roots & & & & \\
\hline & \multicolumn{2}{|c|}{ — Percentage } & 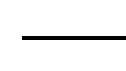 & Days & - & \\
\hline 1 & $98.5 \mathrm{ab}^{\dagger}$ & $1.4 \mathrm{~b}$ & $8.1 \mathrm{~b}$ & $2.1 \mathrm{~b}$ & $7.9 \mathrm{a}$ & $86.3 \mathrm{~b}$ \\
\hline 2 & $94.5 \mathrm{bc}$ & $13.0 \mathrm{a}$ & $8.2 \mathrm{~b}$ & $4.7 \mathrm{a}$ & $7.3 \mathrm{~b}$ & $82.6 \mathrm{c}$ \\
\hline 3 & $98.6 \mathrm{a}$ & $13.5 \mathrm{a}$ & $6.8 \mathrm{c}$ & $1.0 \mathrm{~b}$ & $6.7 \mathrm{c}$ & $89.9 \mathrm{a}$ \\
\hline 4 & $93.9 \mathrm{c}$ & $1.4 \mathrm{~b}$ & $8.8 \mathrm{a}$ & $1.3 \mathrm{~b}$ & $8.3 \mathrm{a}$ & $78.5 \mathrm{~d}$ \\
\hline
\end{tabular}

${ }^{\dagger}$ Means within a column followed by the same letter are not significantly different based on $\operatorname{LSD}(P=0.05)$. 


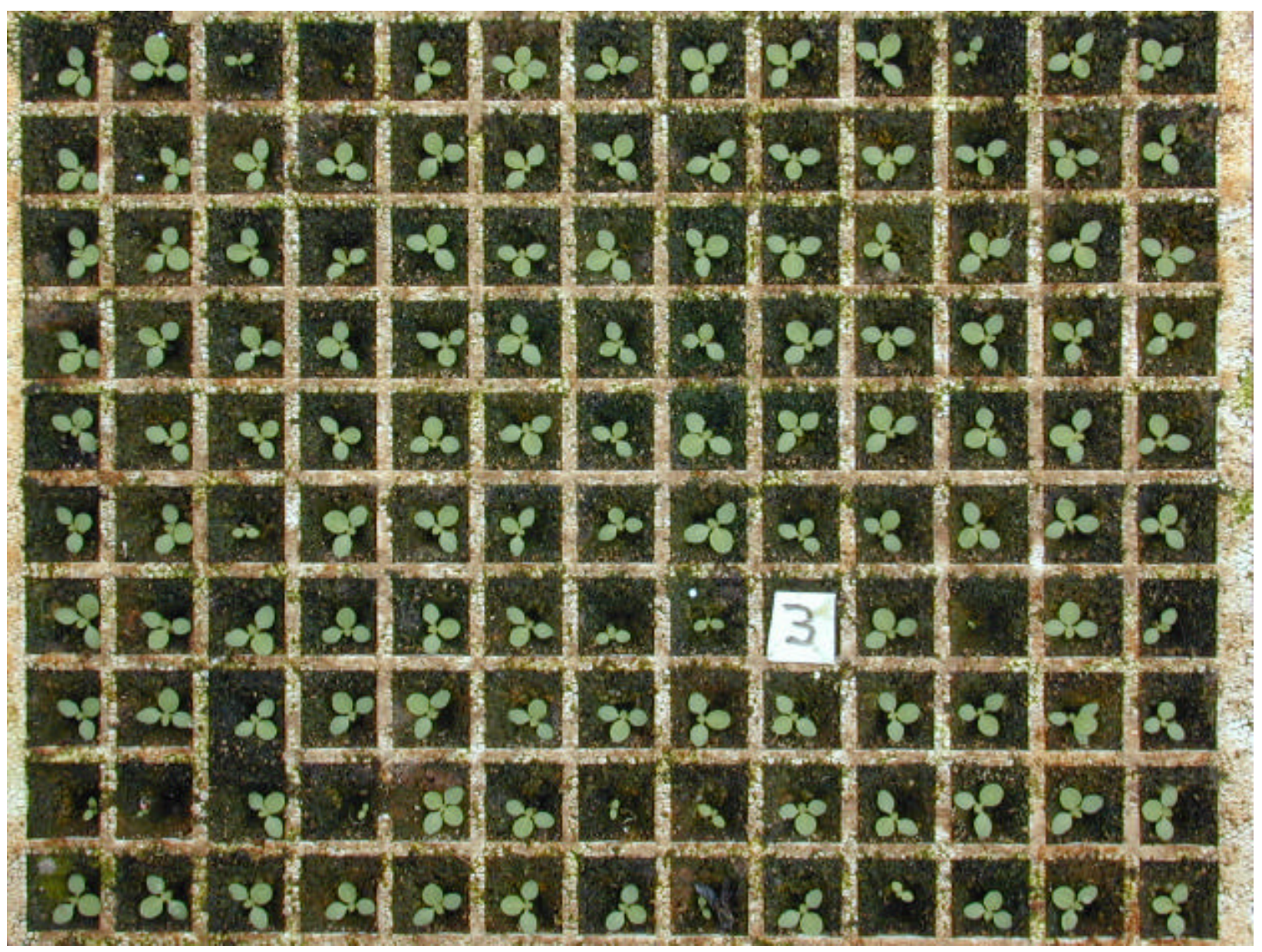

Figure 3.1 Example image of tray at 14-d after seeding, Lynch greenhouse, Brunswick County, Virginia. 


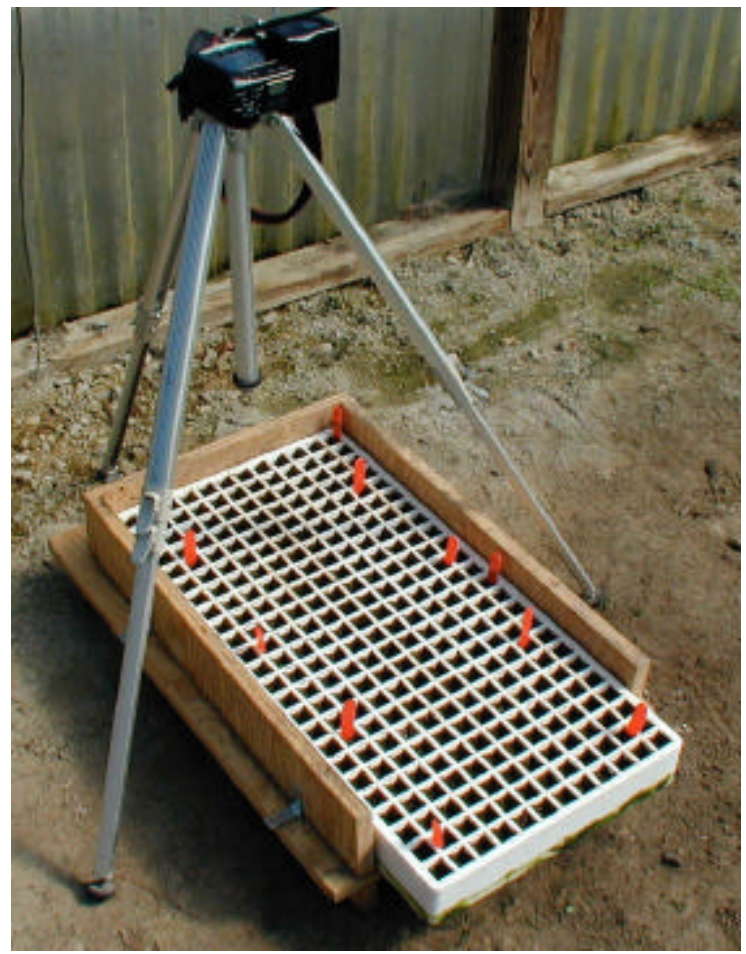

Figure 3.2. Acquisition of image of one seed lot. 


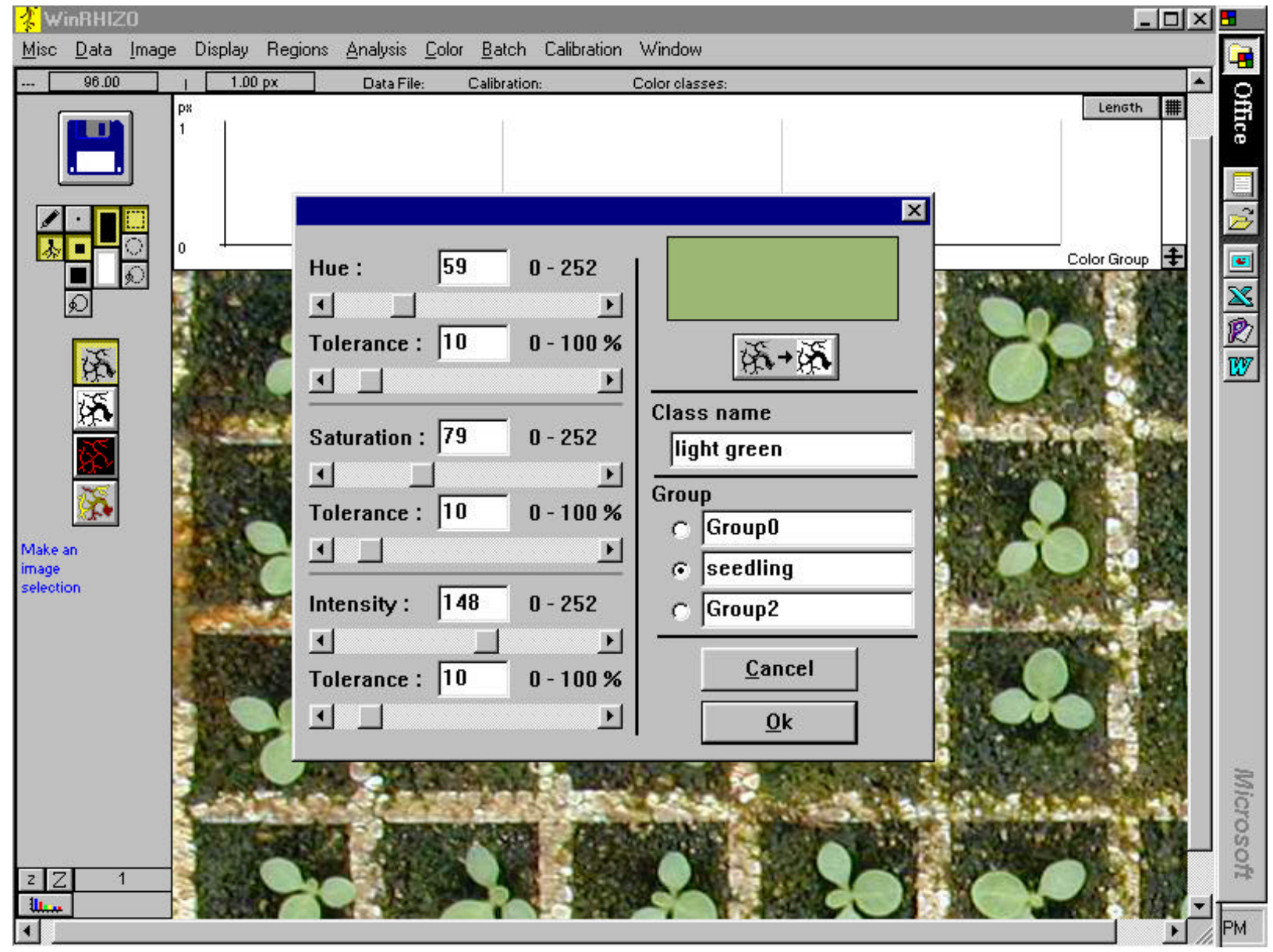

Figure 3.3 Selection of color classes for leaf area analysis. 


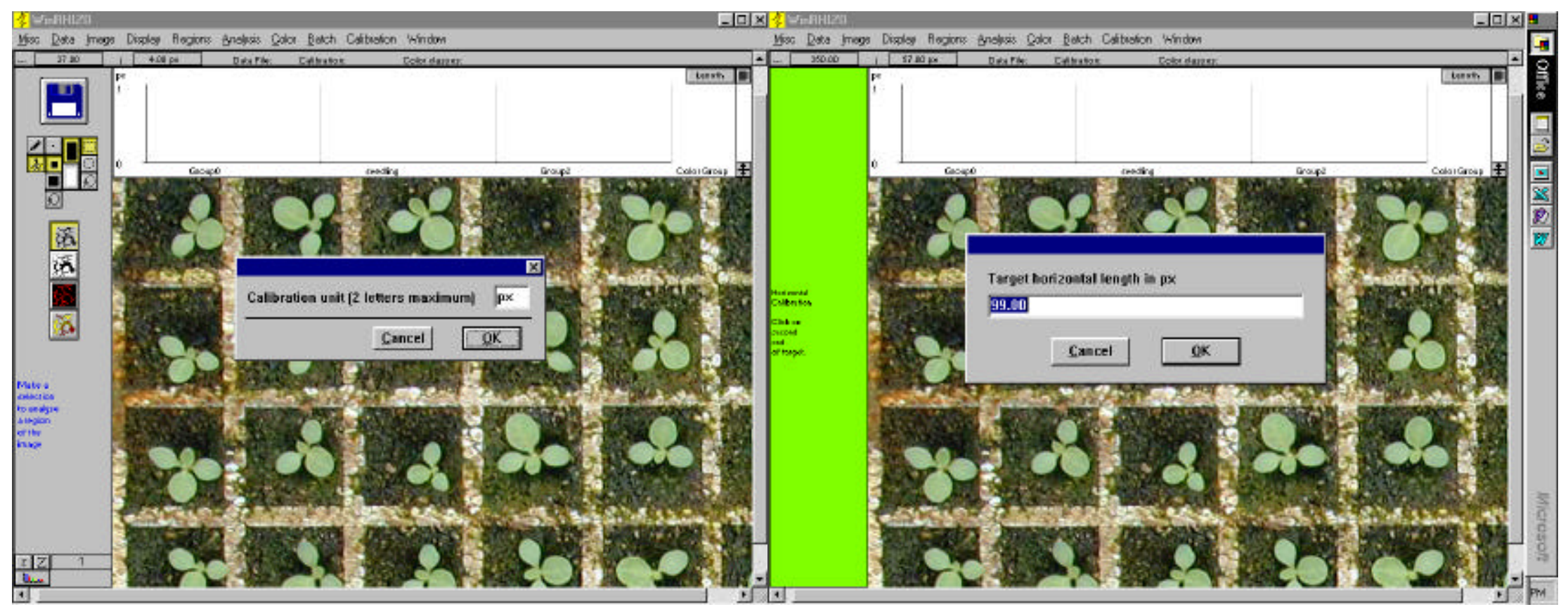

Figure 3.4 Calibration of software for leaf area analysis from image. 


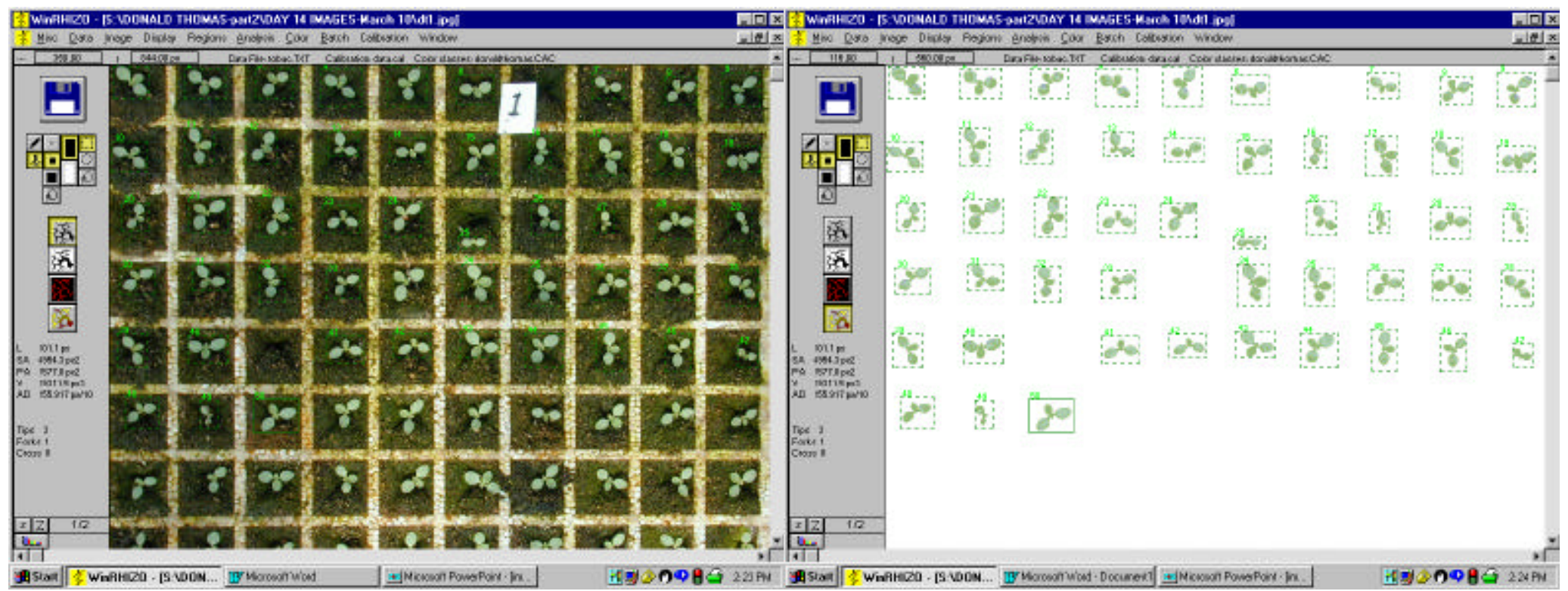

Figure 3.5. Image of relatively uniform seed lot with a calculated SPI $=90.7 . \quad\left(n=50\right.$; mean leaf area $a_{\max }=$ 1604.5; mean leaf area $_{i}=1246.1$; s.d. $=346.7 ; \mathrm{CV}=0.278 ; 14-\mathrm{d}$ stand $=0.985$ ). 


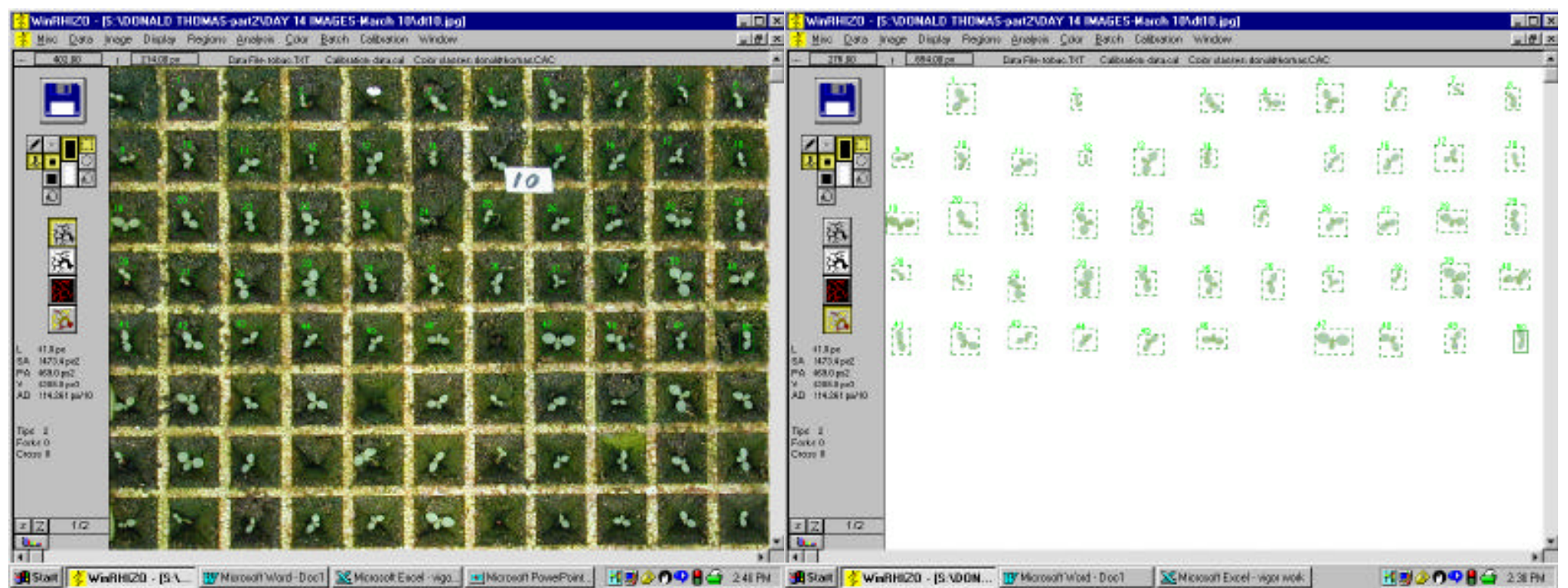

Figure 3.6. Image of relatively nonuniform seed lot with a calculated SPI $=75.8$. $\left(\mathbf{n}=50\right.$; mean leaf area $a_{\max }=$ 1604.5; mean leaf area $_{i}=529.4 ;$ s.d. $=255.7 ; C V=0.483 ; 14-d$ stand $=0.985$ ). 


\title{
Chapter IV
}

\section{Using a Seedling Performance Index to Evaluate Greenhouse Tobacco Seedling Production}

\begin{abstract}
A greenhouse tobacco seedling performance index (SPI) was developed to quantitatively describe seedling size and uniformity, qualities that can only be subjectively inferred from germination and vigor tests. The objective of this study was to examine the effects of seed pellet material, seed priming, and media on flue-cured tobacco seedling performance using the SPI as a quantitative descriptor. Greenhouse tobacco seed trials demonstrated that, although seed pelleted with the Rickard pellet material had a higher emergence, it also had a consistently higher spiral root incidence, which contributed to a significantly lower SPI for all cultivars compared to the Cross Creek pellet material. Primed seed lots of two flue-cured cultivars (NC 71 and NC 72) had a significantly higher SPI than the nonprimed seed lots at one location, but not at a second location. No significant differences were observed in the SPI for primed and nonprimed seed lots of flue-cured tobacco cultivar RG 17. The effects of priming tobacco seed were inconclusive. Seed lots sown in Carolina Choice, Carolina Gold, and Sunshine LP5 commercial media had a higher SPI and lower spiral root incidence than when sown in Premier Pro-Mix TA commercial medium. Results of these studies suggest that the SPI quantitatively describes the differences observed in seedling performance due to production variables even though all seed lots evaluated were certified with $90 \%$ germination. Therefore, the SPI effectively depicts seedling performance in a greenhouse environment.
\end{abstract}




\section{Introduction}

Greenhouses are used to produce most tobacco transplants in the USA and Canada; and the use of float system greenhouses is increasing in countries such as Australia, Brazil, and Italy (Peedin, 1999). Float system greenhouses are used to produce approximately $98 \%$ of the tobacco transplants for Virginia's flue-cured tobacco acreage (Reed et al., 2001).

The change from outdoor plant beds to greenhouses for tobacco transplant production has increased awareness of the importance of seed quality. Tobacco growers typically seeded outdoor plant beds with five times more seeds than the amount of transplants that would be used; but in a greenhouse, an excess of only $10 \%$ to $15 \%$ more seed will be sown. Growers determine the extra amount to be sown based on the purchase of seed with a certified $90 \%$ germination, but germination tests do not always accurately portray how seed lots will perform in the greenhouse. Nonuniform, delayed, prolonged, and poor emergence are common problems in the greenhouse with seed lots that have certified $90 \%$ germination. Spiral roots are also a common occurrence in greenhouses. Spiral rooted seedlings result in a root that does not readily penetrate the media surface. Spiral roots are directly related to seedling performance, because these abnormal seedlings may not survive, or they may survive but be smaller and unsuitable for transplanting (Reed et al., 2001).

Greenhouse production typically requires pelleting tobacco seed. Tobacco seed are very small, so they are pelleted for use with mechanical seeders. The pellet material is composed of a selected clay mixed with a binder and/or water (Cantliffe, 2000). Pelleting changes the overall shape and size of the seed. Fluorescent dyes used in pelleting allow the seed to be more visible in the plug tray after seeding (Styer and Koranski, 1997). Commercial tobacco seed is pelleted by perhaps as many as four different companies. Styer and Koranski (1997) reported that pellets from different companies have different properties, 
such as water uptake, pellet dissolution, and coloring. The color of the pellet is simply for visual purposes and should not interfere with water uptake or seedling emergence. The seed pellet is a boundary that water must permeate before the seed can germinate, and moisture needs to be kept uniform throughout the first two phases of germination; because, if pellets dry out, the seedling may die. Generally, pelleting slows down germination by a day because of the time it takes water to permeate the pellet (Styer and Koranski, 1997). Delayed and prolonged emergence results in nonuniform seedling stands. Poor emergence may be the result of inadequate moisture reaching the germinating seed. Seedling performance often reflects the effect of the pellet on the emerging seedlings.

In the greenhouse float system, tobacco seed is placed on the surface of soilless media in styrofoam trays and left uncovered. Water must first be absorbed by the medium and then permeate the pellet. Poor emergence results when the soilless medium does not adsorb enough water, so the surface of the medium, where the seed is located, remains dry. The reason that the medium exhibits this tendency may be due to the amount of surfactant/wetting agent in the medium mixture, which enables the medium to adsorb water more readily. Media are composed of peat, vermiculite, and perlite, which also affect water adsorbing properties. The peat component of the mixture is hydrophobic, so it is necessary to add a wetting agent to increase the water adsorption of the medium (Reed, 1996). Soilless media used in float transplant production are not stored from year to year, but manufactured during the season it will be used, due to the volatility of the wetting agent in the media. The wetting agent is not stable and breaks down with normal storage conditions; so, if producers use media from the previous season they are more likely to have problems with poor water adsorption. Spiral root incidence is often higher in brands of media that tend to be dry on the surface, because there is inadequate moisture to break down the seed pellet completely. Excessive moisture is also a negative factor in seedling growth 
because inadequate aeration may increase spiral root incidence (Reed et al., 2001).

Priming seed is a process that hydrates seed so that germination begins, but radical emergence does not occur. The process of priming aids seed through the physiological processes of the first two phases of germination that may be difficult to overcome, so that all seed are at the same beginning point when imbibition occurs. The desired result is that upon imbibition, a uniformly emerging population will occur (Welbaum, 1998). However, tobacco seed has shown inconsistent results to priming. Nonuniform seedling growth is common with primed seed (Hutchens, 1999). The objectives of these studies were to determine the effect of different greenhouse production factors on seed lots by examining emergence, spiral roots, germination rates, and the ability of the greenhouse tobacco seedling performance index to adequately describe seedling performance.

\section{Materials and Methods}

Studies were conducted in a greenhouse at Southern Piedmont Agricultural Research and Extension Center (SPAREC) and in grower greenhouses in Brunswick (Thomas and Harrison), Pittsylvannia (Emerson), and Mecklenburg (Clary) counties. Either 288- or 338-cell styrofoam float trays (Radva, Radford, VA) were used in each trial. Trays were filled with commercial soilless media used in float system greenhouses. Harrison, Clary, and SPAREC seed trials utilized Carolina Choice (Carolina Soil Company, Kinston, NC) commercial media. Several different media were used in seed trials at Thomas and Emerson. All seed trials were seeded in February and March 2001. Float trays were seeded using a Berry (Elizabeth City, NC) rolling seeder at all locations, except Emerson and SPAREC, where a half-tray seeder (Carolina Soil Company, Kinston, NC) was used. A Berry automatic media-filling box was used to fill the trays at Emerson and SPAREC. Each trial was conducted in a 
randomized complete block design with four or six replications. Each replication consisted of either a whole or half tray of each treatment. Trays were placed in the center of the greenhouse to minimize temperature differentials observed between the center and outside edge of the greenhouse. When necessary, four trays were placed between the trial and the greenhouse side curtain.

One study conducted at Thomas and SPAREC examined the effects of pellet material and cultivars on seedling performance. An original seed lot from each cultivar was divided into seed pelleted by Cross Creek Pelleting and F.W. Rickard Seeds. The Cross Creek pellet is a melt down type pellet and the Rickard pellet is a split-coat type pellet. Another study at Clary and Harrision examined the effects of priming on seedling performance of three flue-cured tobacco cultivars. One seed lot from each cultivar was divided into seed that was primed or remained nonprimed. F.W. Rickard Seeds pelleted all seed lots in the priming trials. An additional test at Thomas examined two seed lots of flue-cured tobacco in five media. The media examined were Carolina Choice (2001 growing season), Sunshine LP5 (Sun Gro Horticulture, Elizabeth City, NC), Premier ProMix TA (Quebec, Canada), Carolina Gold (Tampa, FL), and Carolina Choice (2000 growing season). The treatment design was arranged in a two (seed lots) $\mathrm{x}$ five (media) factorial. Two separate trials at Emerson examined four seed lots of two flue-cured tobacco cultivars (NC 71 and NC 297) in four media. The media examined were Carolina Choice (2001), Premier Pro-Mix TA, Carolina Gold, and Speedling (Tampa, FL). A four (seed lots) $\mathrm{x}$ four (media) factorial treatment arrangement was used for each trial.

Number of seedlings emerged were counted 7, 8, 9, 10, 12, and $14 \mathrm{~d}$ after seeding in all trials with the exception of the Emerson trial. Emergence is defined as cotyledon expansion. Spiral roots were counted at 12 and $14 \mathrm{~d}$ after seeding at all trials except for Emerson. One image was taken of each tray in each trial at 14 $\mathrm{d}$ after seeding. Images were taken with a CoolPix 950 (Nikon, Richmond, VA) 
digital camera at a resolution of 1024 x 840 pixels. The float tray was placed in wooden box beneath the camera mounted on a tripod. The first fifty seedlings were selected for leaf area analysis from approximately 130 cells captured on an image. Cells with missing seedlings or seedlings not projecting a horizontal surface, such as those emerging in the corner of a cell, were avoided for leaf area analysis. The leaf area data obtained from digital analysis was saved in a Microsoft Excel file. The images were analyzed using WinRHIZO (Ver. 4.1 Pro) (Regent Instruments, Inc., Quebec, Quebec), which measures the leaf area of the cotyledons and the first true leaves if present at $14 \mathrm{~d}$ after seeding using color classes.

The greenhouse tobacco seedling performance index (SPI) was calculated for all seed lots. Development of the SPI was described previously (Chapter III). Probit analysis was performed using SigmaPlot (2000, SPSS, Chicago, Illinois) to graphically determine T50 (mean time to germination). The germination index (GI) (Scott et al., 1984) was also calculated. The germination index is calculated as:

$$
\mathrm{GI}=\sum \mathrm{T}_{\underline{i}} \underline{\mathrm{x}} \mathrm{N}_{\mathrm{i}}
$$

where $T_{i}$ is the number of days after sowing, $N_{i}$ is the number of seeds germinated on day $\mathrm{i}$, and $\mathrm{S}$ is the total number of seeds sown.

An analysis of variance was performed using PROC ANOVA in SAS for the seed lot trials at Thomas and Emerson (SAS Institute, 2000). Treatment means for the Thomas and Emerson seed lot/media trials, and the seed pellet trial at Thomas and SPAREC with Fisher's Least Significant Difference test. Treatment means were separated for the priming trial at Harrison and Clary using PROC TTEST in SAS. 


\section{Results and Discussion}

Pellet material. There were significant treatment by location interactions, so data for each trial is presented separately. There was no significant pellet by cultivar interaction within each trial, therefore only main effects data will be presented. Emergence at $14 \mathrm{~d}$ after seeding was higher for the Rickard pellet in each test, but was significantly higher at the Thomas greenhouse (Tables 4.1 and 4.2). Spiral root incidence was significantly lower for the Cross Creek pellet compared to the Rickard pellet in both trials. Spiral root incidence was greater overall at SPAREC than at the Thomas greenhouse.

The T50 was significantly lower for the Cross Creek pellet compared to the Rickard pellet at SPAREC, but no difference existed at Thomas. The GI was significantly higher for the Rickard pellet at SPAREC, but there was no significant difference between pellet materials for the GI at Thomas. A lower GI and lower T50 are indicative of quicker germination rates, so despite having achieved 50\% emergence more quickly, the Cross Creek pellet took slightly longer to reach maximum germination at SPAREC. The SPI was significantly higher for the Cross Creek pellet in both tests. Higher spiral root incidence lowered the SPI for the Rickard pellet at both SPAREC and Thomas. The lower

spiral root incidence and quicker germination rate for the Cross Creek pellet in the SPAREC trial contributed to a larger and more uniform seedling population that resulted in a significantly higher SPI than for the Rickard pellet.

There were no significant differences in emergence among cultivars at either location. At Thomas, SP NF3 had a significantly higher spiral root incidence than SP 172 and SP 179, and SP 168 was not significantly different from any of the other three cultivars. SP 172 had a significantly lower spiral root incidence than SP 168 and SP 179 at SPAREC, but was not significantly different from SP NF3. SP 179 had a significantly higher T50 than the other three cultivars at Thomas, but at SPAREC was not significantly different from SP NF3. No 
significant difference existed in the T50 of SP 168 and SP 172, and SP 172 was not significantly different than SP 179 at the SPAREC greenhouse. At the Thomas greenhouse, no significant difference existed in the T50 between SP 168 and SP NF3, although SP 172 was significantly lower than both cultivars. No significant differences existed in the GI for any of the cultivars at SPAREC. The GI for SP 172 was significantly higher than SP 179 and SP NF3, but not SP 168, which was also not significantly different from SP 179 at the Thomas trial. No significant differences existed in the SPI among cultivars at Thomas. The SPI of SP NF3 was significantly lower than SP 168 and SP 172, but SP 179 was not significantly different than the other three cultivars at SPAREC. Slower germination rates and higher spiral root incidence for SP NF3 and SP 179 resulted in lower SPI values at SPAREC.

Priming. Data for each trial is presented separately due to a significant treatment by location interaction. There was a significant priming by cultivar interaction, so the data for each priming treatment will be presented by cultivar. Emergence at $14 \mathrm{~d}$ after seeding was significantly higher for the primed $\mathrm{NC} 71$ at both locations. Primed NC 72 and RG 17 seed lots at Harrison also had higher emergence at $14 \mathrm{~d}$ although the differences were not significant (Table 4.3 and 4.4). No significant differences existed for 14-d emergence for NC 72 and RG 17 seed lots at Clary. Spiral root incidence was significantly higher for the nonprimed NC 72 seed lot in both trials and the primed RG 17 and NC 71 at Clary. The primed RG 17 also had a higher spiral root incidence, although nonsignificant, at the Harrision greenhouse. No significant differences existed in spiral root incidence for the NC 71 seed lots at Harrison.

A T50 value could not be measured for the primed NC 71 and NC 72 seed lots at Clary because greater than $50 \%$ emergence had occurred before the first count. When the T50 could be calculated, the T50 for the primed seed lots for all cultivars was significantly lower at both locations, indicating the rapid early 
emergence associated with primed seed. The GI was significantly lower for the primed seed lots for all cultivars at both locations, except for the primed RG 17 seed lot at the Harrison greenhouse. The lower GI values support the rapid emergence of primed seed that was observed.

No significant differences existed in the SPI for the RG 17 seed lots in either trial. The primed RG 17 seed lot did emerge earlier, which resulted in larger seedlings, but the higher spiral root incidence associated with the seed lot resulted in a nonuniform seedling population that resulted in a SPI similar to the smaller, more uniform nonprimed seed lot. The SPI for the primed NC 72 seed lot was higher at both greenhouses, but was significantly higher at the Clary greenhouse. The nonprimed NC 72 seed lot had a significantly higher spiral root incidence and the increased spiral roots contributed to a lack of uniformity, which lowered the SPI for this seed lot. The marginal performance of the nonprimed NC 71 seed lot resulted in a significantly lower SPI at the Clary greenhouse. The poor performance of the nonprimed NC 71 at both locations indicated a weaker seed lot that was more sensitive to variation in greenhouse conditions.

Seed lot/Media. There was a significant cultivar by media interaction with respect to emergence and spiral roots at the Thomas greenhouse, therefore data for each cultivar is presented separately (Table 4.5). The 14-d emergence of both cultivars did not differ significantly among the five media. Overall emergence was higher for SP H20 than SP 168. Both cultivars had significantly more spiral roots in the Premier Pro-Mix TA media compared to the other four media. Spiral root incidence in the Carolina Choice (2000) was not significantly different from Premier Pro-Mix TA for SP H20.

The T50 was significantly higher for both cultivars in the Carolina Choice (2000) indicating a slower germination rate. The Carolina Choice (2000) absorbed water more slowly and remained drier throughout the germination period, so emergence was slower due to inadequate moisture available to dissolve 
the pellet. The wetting and drying cycles of this media also contributed to the higher spiral root incidence. There were no differences among media for the GI in either cultivar. The GI value was low for both cultivars in all media indicating rapid emergence overall.

Both SP H20 and SP 168 had a significantly higher SPI in the Carolina Choice (2001), Carolina Gold, and Sunshine LP5 media because of the significantly lower T50 and spiral roots. The high spiral root incidence in the Premier Pro-Mix TA and Carolina Choice (2000) contributed to nonuniform growth that lowered the SPI.

A significant seed/media interaction existed for the SPI in both trials (Tables 4.6 and 4.7) at the Emerson greenhouse, so data for each seed lot is presented separately. There was a significantly lower SPI of the NC 71 seed lot A grown in Speedling media as compared to the other three media (Table 4.6). There were no significant differences among media in the SPI of the NC 71 seed lots B or C. No difference existed in the SPI of the NC 71 seed lot D between Carolina Gold and Premier Pro-Mix TA, but the Speedling media had a significantly lower SPI than both media. The Carolina Choice (2001) media did not differ significantly from the other three media.

There were no significant differences in the SPI of the NC 297 seed lots A, B, or D among the media. No significant differences existed for the SPI of the NC 297 seed lot C between Carolina Gold and Carolina Choice (2001) or between Premier Pro-Mix TA and Speedling. The SPI for NC 297 seed lot C was significantly lower for the Premier Pro-Mix TA and Speedling compared to Carolina Choice (2001) and Carolina Gold.

Summary. All seed lots tested were commercially available with a certified $90 \%$ germination. A greenhouse tobacco seedling performance index (SPI) did detect significant differences among seed lots in the trials conducted. Seed lots with equal 14-d emergence were found to be significantly different in 
seedling performance. The results of these studies indicate that differences in seed lot performance related to greenhouse production factors can be determined by leaf area analysis.

Pelleting seed increases the size and allows for easier and more accurate seeding, but generally decreases the germination rate. Seed companies are refining their pellet constantly to improve how quickly the pellet dissolves in order to obtain high germination and uniformity (Styer and Koranski, 1997). The results of this study are only descriptive for the seed lots used in the trials because companies are constantly trying to improve their product. Seed lots purchased next year may have a different pellet material. Although pellet material may differ from one year or one seed lot compared to another, the SPI quantitatively describes seedling growth after emergence from a particular pellet with one measurement. The SPI could be used to depict seedling performance of future pellet material.

Priming has been demonstrated to positively benefit muskmelon seeds and other species by increasing the temperature range for germination, but priming can also negatively affect seed. After the priming process is complete, rapid drying may damage the seed and therefore reduce seedling growth rates. The variable effects of priming have become increasingly obvious (Welbaum et al., 1998). The SPI effectively measured the different effects of priming on tobacco seed by measuring emergence, size, and uniformity of seedlings. A widespread effect of priming is an increased germination rate (Welbaum et al., 1998). Priming seed lots did increase the germination rate at all locations, but despite the quicker emergence, seedling growth was often slow and nonuniform, which was reflected in the lower SPI. The SPI can be applied as a quantitative descriptor of the effect of priming, but cannot indicate potential results, due to the inconsistent results from priming. 
Media influence seedling performance significantly by contributing to spiral root incidence and seedling growth rates. Manufacturers change media composition from year to year, therefore the results of these studies are only applicable to these media. The SPI cannot predict how a seed lot will perform in a particular media, if the media is constantly changing. Although the SPI cannot predict seedling performance in a particular media, differences in seedling performance can be detected in media. The SPI could benefit media companies by quantitatively describing seedling performance in different media compositions.

Priming, pellet materials, and media influence seedling performance under greenhouse conditions. The seed pellet and media are production factors that are integral to greenhouse tobacco transplant production. As a result, seed lot performance differs. The SPI demonstrated that both priming and pelleting influence seedling performance, although the effects of priming on seedling performance were inconsistent. Priming is an option that growers should avoid because of the contradictory results obtained. More research needs to be completed on the effects of pelleting, priming, and media on tobacco seed performance. Production factors do not influence germination in a controlled germination test, so the primary advantage of the SPI is to classify the seedling performance of a seed lot as well as the germination, so a person purchasing the seed would know how the seed performed under greenhouse conditions.

\section{Acknowledgements}

We thank Carolina Soil Company, Kinston, North Carolina; Chuck Miglianti, Tampa, Florida; and Aaron Creek Farms, Buffalo Junction, Virgnia for providing the media to conduct research. We also express our appreciation to Carolina Soil Company for providing the half-tray seeder used for research. We extend our gratitude to Cross Creek Pelleting, Raeford, North Carolina; F.W. Rickard Seeds, Winchester, Kentucky; Gold Leaf Seed Company, Hartsville, 
South Carolina; and Speight Seeds, Wintersville, North Carolina for providing the seed lots used in the seed trials. 


\section{References}

Cantliffe, D. 2000. Understanding seed physiology from a grower's viewpoint. p.94-102. In J. VanderVelde (ed.) Growers Talks on Plugs 3. Ball Publ., Batavia, IL.

Huthchens, T.W. 1999. Tobacco seed. p. 66-9. In D.L. Davisand M.T. Nielsen (ed.) Tobacco: Production, chemistry, and technology. Blackwell Science, London, UK.

Peedin, G.F. 1999. Production practices. 5A Flue-cured tobacco. p. 104-42. In D.L. Davis and M.T. Nielsen (ed.) Tobacco: Production, chemistry, and technology. Blackwell Science, London, UK.

Reed, D.W. 1996. A grower's guide to water, media, and nutrition for greenhouse crops. Ball Publ., Batavia, IL.

Reed, T.D., J.L. Jones, C.S. Johnson, P.J. Semtner, and C.A. Wilkinson. 2001. 2001 Flue-cured tobacco production guide. Pub 436-048. VA Agric. Exp. Stn., Blacksburg, VA.

SAS Institute. 2000. The SAS system for Windows. Release 8.0. SAS Inst., Cary, NC.

Styer, R.C., and D.S. Koranski. 1997. Plug and transplant production: A growers guide. Ball Publ., Batavia, IL.

Welbaum, G.E., Z. Shen, M.O.Oluoch, and L.W. Jett. 1998. The evolution and effects of priming vegetable seeds. J. Seed Technol. 20: 209-35. 
Table 4.1. Effect of pellet material and cultivars on seedling performance, Thomas greenhouse, Brunswick County, Virginia.

\begin{tabular}{|c|c|c|c|c|c|}
\hline \multirow[b]{2}{*}{ Pellet } & \multicolumn{2}{|c|}{$14-d$} & \multirow[b]{2}{*}{$\mathrm{T} 50$} & \multirow[b]{2}{*}{ GI } & \multirow[b]{2}{*}{ SPI } \\
\hline & Emerg. & Sp. Root & & & \\
\hline & $-\mathrm{Pe}$ & age & _ Days & - & \\
\hline \multicolumn{6}{|l|}{ Pellet } \\
\hline Rickard & $95.6 \mathrm{a}^{\dagger}$ & $6.0 \mathrm{a}$ & $8.4 \mathrm{a}$ & $6.6 \mathrm{a}$ & $72.7 \mathrm{~b}$ \\
\hline Cross Creek & $92.0 \mathrm{~b}$ & $0.5 \mathrm{~b}$ & $8.5 \mathrm{a}$ & $6.8 \mathrm{a}$ & $76.1 \mathrm{a}$ \\
\hline \multicolumn{6}{|l|}{ Cultivar } \\
\hline SP 168 & $92.6 \mathrm{a}^{\dagger}$ & $3.2 \mathrm{ab}$ & $8.5 \mathrm{~b}$ & $6.8 \mathrm{ab}$ & $74.7 \mathrm{a}$ \\
\hline SP 172 & $94.1 \mathrm{a}$ & $1.9 \mathrm{~b}$ & $7.8 \mathrm{c}$ & $6.9 \mathrm{a}$ & $74.5 \mathrm{a}$ \\
\hline SP 179 & $92.9 \mathrm{a}$ & $2.9 \mathrm{~b}$ & $9.3 \mathrm{a}$ & $6.5 \mathrm{c}$ & $73.8 \mathrm{a}$ \\
\hline SP NF3 & $95.5 \mathrm{a}$ & $5.0 \mathrm{a}$ & $8.2 \mathrm{~b}$ & $6.6 \mathrm{bc}$ & $74.6 \mathrm{a}$ \\
\hline
\end{tabular}

${ }^{\dagger}$ Means within a column within a grouping followed by the same letter are not significantly different when tested by LSD $(P=0.05)$. 
Table 4.2. Effect of pellet material and cultivars on seedling performance, SPAREC greenhouse, Nottoway County, Virginia.

\begin{tabular}{|c|c|c|c|c|c|}
\hline \multirow[b]{2}{*}{ Pellet } & \multicolumn{2}{|c|}{$14-d$} & \multirow[b]{2}{*}{$\mathrm{T} 50$} & \multirow[b]{2}{*}{ GI } & \multirow[b]{2}{*}{ SPI } \\
\hline & Emerg. & Sp. Root & & & \\
\hline & $-\mathrm{Pe}$ & age $\longrightarrow$ & _ Days & 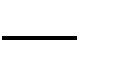 & \\
\hline \multicolumn{6}{|l|}{$\underline{\text { Pellet }}$} \\
\hline Rickard & $94.1 \mathrm{a}^{\dagger}$ & $13.0 \mathrm{a}$ & $7.2 \mathrm{a}$ & $6.3 \mathrm{a}$ & $71.2 \mathrm{~b}$ \\
\hline Cross Creek & $92.7 \mathrm{a}$ & $1.7 \mathrm{~b}$ & $5.9 \mathrm{~b}$ & $6.0 \mathrm{~b}$ & $83.2 \mathrm{a}$ \\
\hline \multicolumn{6}{|l|}{$\underline{\text { Cultivar }}$} \\
\hline SP 168 & $93.5 \mathrm{a}^{\dagger}$ & $9.7 \mathrm{a}$ & $6.2 \mathrm{c}$ & $6.1 \mathrm{a}$ & $78.0 \mathrm{a}$ \\
\hline SP 172 & $92.6 \mathrm{a}$ & $4.7 \mathrm{~b}$ & $6.4 \mathrm{bc}$ & $6.1 \mathrm{a}$ & $79.0 \mathrm{a}$ \\
\hline SP 179 & $93.5 \mathrm{a}$ & $8.1 \mathrm{a}$ & $6.7 \mathrm{ab}$ & $6.2 \mathrm{a}$ & $76.8 \mathrm{ab}$ \\
\hline SP NF3 & $93.9 \mathrm{a}$ & $6.9 \mathrm{ab}$ & $6.9 \mathrm{a}$ & $6.1 \mathrm{a}$ & $74.9 \mathrm{~b}$ \\
\hline
\end{tabular}

${ }^{\dagger}$ Means within a column within a grouping followed by the same letter are not significantly different when tested by $\operatorname{LSD}(P=0.05)$. 
Table 4.3. Effect of priming on seedling performance of three flue-cured tobacco cultivars, Clary greenhouse, Mecklenburg County, Virginia.

\begin{tabular}{|c|c|c|c|c|c|c|}
\hline \multirow[b]{2}{*}{ Seed lot } & \multirow[b]{2}{*}{ Primed } & \multicolumn{2}{|c|}{$14-d$} & \multirow[b]{2}{*}{$\mathrm{T} 50$} & \multirow[b]{2}{*}{ GI } & \multirow[b]{2}{*}{ SPI } \\
\hline & & Emerg. & Sp. Root & & & \\
\hline & & _Per & tage_- & & & \\
\hline \multicolumn{7}{|c|}{$\underline{\text { Cultivar }=\text { NC } 71}$} \\
\hline R71LNC-ZV & No & 79.5 & 6.7 & 9.5 & 7.1 & 70.9 \\
\hline RP71NC-1ZV & Yes & $97.4^{*}$ & $10.6^{*}$ & $\dagger$ & $6.3^{*}$ & $84.5^{*}$ \\
\hline \multicolumn{7}{|c|}{$\underline{\text { Cultivar }=\mathrm{NC} 72}$} \\
\hline RP72LE-2ZI & No & 93.6 & $17.3^{*}$ & 8.0 & 7.8 & 72.2 \\
\hline RP72LE-3ZV & Yes & 92.6 & 7.7 & $\dagger$ & $5.9^{* * *}$ & $78.5^{*}$ \\
\hline \multicolumn{7}{|c|}{ Cultivar $=$ RG 17} \\
\hline RG17JAZI & No & 97.4 & 7.7 & 7.0 & 8.2 & 80.7 \\
\hline RG17JAZV-2 & Yes & 97.1 & $13.1^{*}$ & $5.9^{*}$ & $7.2^{*}$ & 79.2 \\
\hline
\end{tabular}

${ }^{*, * * *}$ Means within a cultivar are significantly different at 0.05 and 0.001 probability levels, respectively based on a $t$-test.

$\dagger$ indicates that germination exceeded $50 \%$ before counts began, so T50 could not be calculated for these seed lots. 
Table 4.4. Effect of priming on seedling performance of three flue-cured tobacco cultivars, Harrison greenhouse, Brunswick County, Virginia.

\begin{tabular}{|c|c|c|c|c|c|c|}
\hline \multirow[b]{2}{*}{ Seed lot } & \multirow[b]{2}{*}{ Primed } & \multicolumn{2}{|c|}{$14-d$} & \multirow[b]{2}{*}{ T50 } & \multirow[b]{2}{*}{ GI } & \multirow[b]{2}{*}{ SPI } \\
\hline & & Emerg. & Sp. Root & & & \\
\hline & & —Per & tage-_ & & & \\
\hline \multicolumn{7}{|c|}{ Cultivar $=$ NC 71} \\
\hline R71LNC-ZV & No & 91.7 & 7.4 & 9.1 & 8.8 & 82.0 \\
\hline RP71NC-1ZV & Yes & $96.8^{*}$ & 7.4 & $6.5^{*}$ & $6.8^{*}$ & 80.7 \\
\hline \multicolumn{7}{|c|}{ Cultivar $=$ NC 72} \\
\hline RP72LE-2ZI & No & 94.9 & $20.2^{*}$ & 8.6 & 8.4 & 65.7 \\
\hline RP72LE-3ZV & Yes & 96.2 & 5.8 & $6.3^{* * * *}$ & $6.7^{* * *}$ & 68.2 \\
\hline \multicolumn{7}{|c|}{ Cultivar $=$ RG 17} \\
\hline RG17JAZI & No & 96.8 & 7.4 & 7.9 & 7.9 & 76.8 \\
\hline RG17JAZV-2 & Yes & 97.8 & 9.9 & $7.3^{* * *}$ & 7.8 & 72.5 \\
\hline
\end{tabular}

${ }^{*, * * *}$ Means within a cultivar are significantly different at 0.05 and 0.001 probability levels, respectively based on a $t$-test. 
Table 4.5. Effect of five media on seedling performance data for two flue-cured tobacco cultivars, Thomas greenhouse, Brunswick County, Virginia.

\begin{tabular}{|c|c|c|c|c|c|}
\hline \multirow[b]{2}{*}{ Media } & \multicolumn{2}{|c|}{ 14-d } & \multirow[b]{2}{*}{$\mathrm{T} 50$} & \multirow[b]{2}{*}{ GI } & \multirow[b]{2}{*}{ SPI } \\
\hline & Emerg. & Sp. Root & & & \\
\hline & —Perc & ntage__ & & & \\
\hline \multicolumn{6}{|l|}{ Cultivar = SP 168} \\
\hline Carolina Choice (2001) & $93.9 \mathrm{a}^{\dagger}$ & $5.1 \mathrm{bc}$ & $8.3 \mathrm{c}$ & $5.8 \mathrm{a}$ & $76.3 \mathrm{a}$ \\
\hline Carolina Choice (2000) & $92.9 \mathrm{a}$ & $9.6 \mathrm{~b}$ & $9.6 \mathrm{a}$ & $5.7 \mathrm{a}$ & $69.5 \mathrm{~b}$ \\
\hline Carolina Gold & $95.5 \mathrm{a}$ & $2.6 \mathrm{c}$ & $8.8 \mathrm{bc}$ & $5.9 \mathrm{a}$ & $75.3 \mathrm{a}$ \\
\hline Premier Pro-Mix TA & $92.3 \mathrm{a}$ & $15.1 \mathrm{a}$ & $9.0 \mathrm{~b}$ & $5.7 \mathrm{a}$ & $70.3 \mathrm{~b}$ \\
\hline Sunshine LP5 & 95.8 a & $5.1 \mathrm{bc}$ & $8.5 \mathrm{bc}$ & $5.9 \mathrm{a}$ & $74.9 \mathrm{a}$ \\
\hline \multicolumn{6}{|l|}{$\underline{\text { Cultivar }=\text { SP H20 }}$} \\
\hline Carolina Choice (2001) & $96.5 \mathrm{a}$ & $2.6 \mathrm{bc}$ & $7.6 \mathrm{c}$ & $6.0 \mathrm{a}$ & $80.3 \mathrm{a}$ \\
\hline Carolina Choice (2000) & $94.2 \mathrm{a}$ & $5.8 \mathrm{ab}$ & $8.3 \mathrm{a}$ & $5.8 \mathrm{a}$ & $75.3 \mathrm{~b}$ \\
\hline Carolina Gold & $95.8 \mathrm{a}$ & $1.0 \mathrm{c}$ & $8.0 \mathrm{~b}$ & $5.9 \mathrm{a}$ & $80.7 \mathrm{a}$ \\
\hline Premier Pro-Mix TA & $97.4 \mathrm{a}$ & $7.7 \mathrm{a}$ & $8.1 \mathrm{~b}$ & $6.0 \mathrm{a}$ & $75.7 \mathrm{~b}$ \\
\hline Sunshine LP5 & $95.8 \mathrm{a}$ & $1.9 \mathrm{c}$ & $7.7 \mathrm{c}$ & $5.9 \mathrm{a}$ & $81.9 \mathrm{a}$ \\
\hline
\end{tabular}

${ }^{\dagger}$ Means within a column within a cultivar followed by the same letter are not significantly different when tested by $\operatorname{LSD}(P=0.05)$. 
Table 4.6. Effect of four media on the seedling performance index of four seed lots of flue-cured tobacco cultivar NC 71, Emerson greenhouse, Pittslyvania County, Virginia.

\begin{tabular}{lllll}
\hline & \multicolumn{5}{c}{ Seed lot } \\
\cline { 2 - 5 } Media & A & B & C & D \\
\hline Carolina Choice (2001) & $66.8 \mathrm{a}^{\dagger}$ & $65.8 \mathrm{a}$ & $73.0 \mathrm{a}$ & $71.7 \mathrm{ab}$ \\
Carolina Gold & $67.5 \mathrm{a}$ & $69.3 \mathrm{a}$ & $73.5 \mathrm{a}$ & $73.9 \mathrm{a}$ \\
Premier Pro-Mix TA & $66.5 \mathrm{a}$ & $67.2 \mathrm{a}$ & $72.8 \mathrm{a}$ & $73.8 \mathrm{a}$ \\
Speedling & $62.0 \mathrm{~b}$ & $61.4 \mathrm{a}$ & $72.0 \mathrm{a}$ & $68.5 \mathrm{~b}$ \\
\hline
\end{tabular}

${ }^{\dagger}$ Means within a column followed by the same letter are not significantly different when tested by $\operatorname{LSD}(P=0.05)$. 
Table 4.7. Effect of four media on the seedling performance index of four seed lots of flue-cured tobacco cultivar NC 297, Emerson greenhouse, Pittslyvania County, Virginia.

\begin{tabular}{lllll}
\hline & \multicolumn{5}{c}{ Seed lot } \\
\cline { 2 - 5 } Media & A & B & C & D \\
\hline Carolina Choice (2001) & $75.8 \mathrm{a}^{\dagger}$ & $64.0 \mathrm{a}$ & $69.9 \mathrm{a}$ & $75.0 \mathrm{a}$ \\
Carolina Gold & $76.5 \mathrm{a}$ & $67.1 \mathrm{a}$ & $70.6 \mathrm{a}$ & $76.1 \mathrm{a}$ \\
Premier Pro-Mix TA & $74.0 \mathrm{a}$ & $62.8 \mathrm{a}$ & $63.6 \mathrm{~b}$ & $73.5 \mathrm{a}$ \\
Speedling & $73.4 \mathrm{a}$ & $63.8 \mathrm{a}$ & $63.6 \mathrm{~b}$ & $74.2 \mathrm{a}$ \\
\hline
\end{tabular}

${ }^{\dagger}$ Means within a column followed by the same letter are not significantly different when tested by $\operatorname{LSD}(P=0.05)$. 


\section{Vita}

Jodie Johnson Clarke was born November 14, 1976 to Mark E. and Molly H. Johnson in Winston Salem, North Carolina. She attended Surry County Public Schools and graduated from Surry Central High School in 1995. She enrolled at Virginia Tech in August 1995 and received a B.S. in Crop and Soil Environmental Sciences with a minor in Agricultural and Applied Economics in May 1999. During the summer before her senior year, she worked as a summer intern at Southern Piedmont Agricultural Research and Extension Center in Blackstone, Virginia. During her senior year, she dual-enrolled in the graduate school of Virginia Tech to pursue a M.S. degree in Crop and Soil Environmental Sciences under the direction of Dr. T. David Reed at the Southern Piedmont Agricultural Research and Extension Center in Blackstone, Virginia. Upon graduating, she accepted a position as Extension Agent, ANR/Farm Business Management in Lunenburg County. She is currently employed with Philip Morris USA, Richmond, VA. 